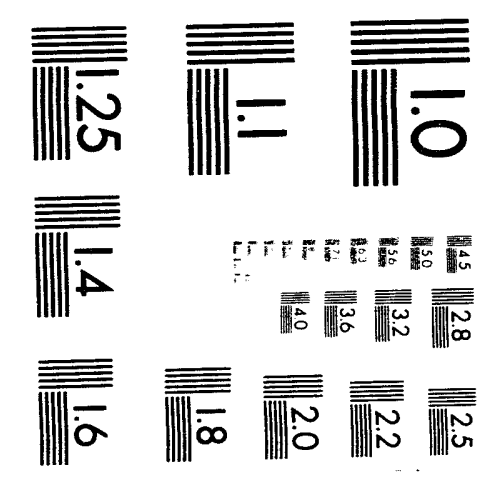



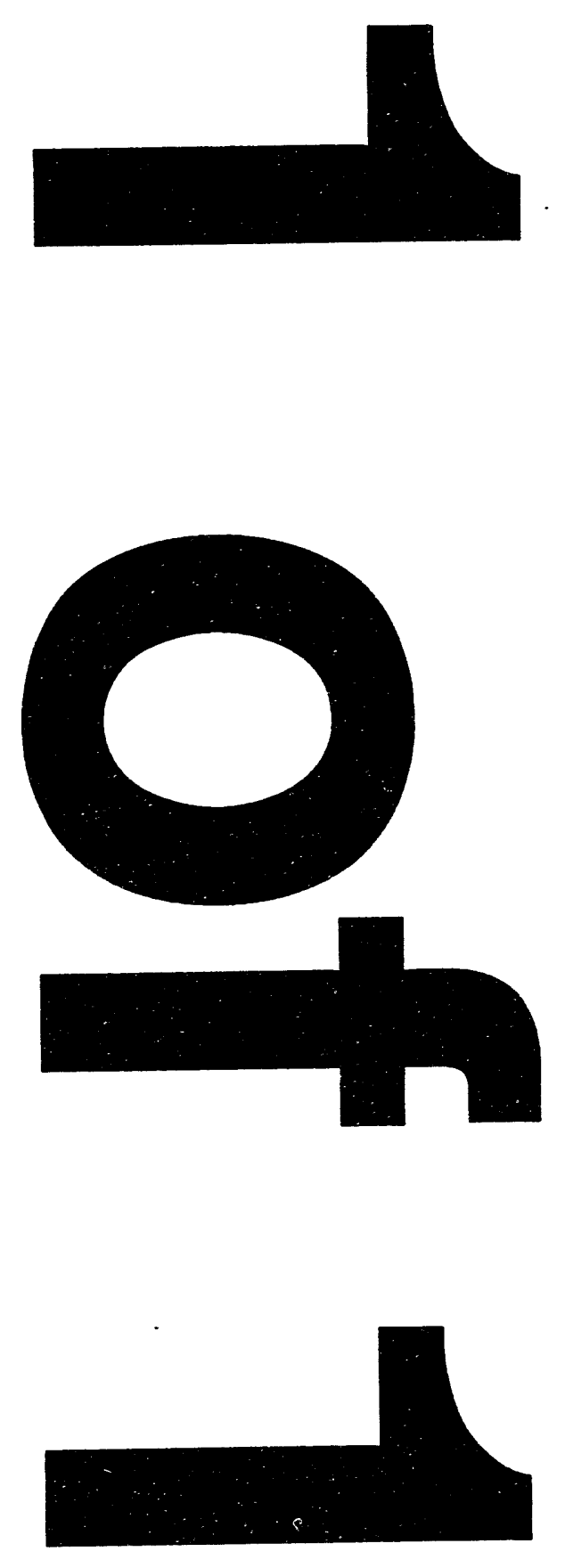


\author{
SAND93-8245 - UC-40 120 \\ Unlimited Release \\ Printed October 1993
}

\title{
THE EFFECT OF PRODUCT!ON TEMPERATURE ON THE RETENTION OF TRITIUM IN VAPOR DEPOSITED BETA SILICON CARBIDE
}

\author{
R. A. Causey \\ Sandia National Laboratories/California \\ and \\ W. R. Wampler \\ Sandia National Laboratories/New Mexico \\ and \\ J. L. Kaae \\ General Atomics \\ San Diago, California 92121
}

\begin{abstract}
This is the final report in the prematurely terminated research program on the behavior of tritium in the NPR-MHTGR tritium target materials. This report addresses the effect of the production temperature of the silicon carbide layer on the tritium permeation characteristics of the silicon carbide. Equilibrium tritium retention measurements performed using samples vapor deposited at $1400^{\circ} \mathrm{C}$ and $1700^{\circ} \mathrm{C}$ were compared to earlier results for samples deposited at $1550^{\circ} \mathrm{C}$. The tritium retention characteristics of the samples produced at $1400^{\circ} \mathrm{C}$ were very similar to the earlier $1550^{\circ} \mathrm{C}$ results. The results for tritium retained in the $1700^{\circ} \mathrm{C}$ produced material was lower by approximately a factor of 3 . The approach to equilibrium was determined for the different materials by outgassing samples that had been exposed to tritium gas at $1200^{\circ} \mathrm{C}$ for different times. No significant differences in th.e time required to reach equilibrium were seen for the silicon carbides deposited at the different temperatures. Extensive research performed at General Atomics on the microstructure of the different materials was used to help explain the behavior differences.
\end{abstract}




\section{The Effect of Production Temperature on the Retention of Tritium in Vapor Deposited Beta Silicon Carbide}

\section{Introduction}

This is the final report in the prematurely terminated research program on the behavior of tritium in the New Production Modular High-Temperature Gas-Cooled Reactor (NPRMHTGR) tritium target materials. The NPR-MHTGR will produce tritium in multilayered microspheres containing lithium aluminate cores. The cores are surrounded by layers of silicon carbide and pyrolytic carbon. For successful operation of the reactor, it is necessary that the tritium be retained in the particles during normal operation, and that the behavior of the tritium in the particles during off-normal operation be understood. It was the original intent of this research program to determine the tritium migration characteristics of both silicon carbide and pyrolytic carbon. Specifically, the original objectives of the research program as listed in the research plan[1] were:

1. Determine the tritium solubility in standard production silicon carbide as a function of temperature and pressure. The term standard production means that the samples will be produced using the same conditions as will be used in the production of the actual tritium targets. The lower temperature will be limited to that which will result in a measurable concentration of deuterium or tritium in the sample. Pressure will be varied only to the point of verification of the square-root of pressure dependence.

2. Determine the intrinsic trap density and energy for the tritium traps in standard production silicon carbide.

3. Determine the tritium diffusion coefficient for standard production silicon carbide over as wide a temperature range as possible.

4. Examine the effect of radiation damage on the tritium trapping for standard producticn silicon carbide. 
5. Perform sufficient experiments on the migration of tritium in pyrolytic carbon to verify the applicability of the diffusion parameters in the literature for tritium in graphite.

6. Examine the effect of variations in the production techniques of the silicon carbide layer on the tritium migration parameters. Variations include silicon carbide deposition ternperature, deposition rate, the fluidized bed coater size, and the amount of aluminum and lithium impurities.

Objectives 1-3 were satisfied in the first two years of the research program and were detailed in an earlier report[2]. Objective 4 was achieved in work just completed using ion damage to duplicate the neutron damage. The ion damage research was performed by W.R. Wampler at Sandia National Laboratories in Albuquerque and is being published[3] concurrently with this report. Objective 5 was not met and must be addressed in the future if this tritium production technique is to be further pursued. For objective 6 , only the variation in the silicon carbide deposition temperature was tested. The results of those tests are detailed in this report. The variations in deposition rate, fluidized bed coater size, and amount of aluminum and lithium impurities were not tested.

This report describes equilibrium tritium retention measurements performed using silicon carbide samples vapor deposited at $1400^{\circ} \mathrm{C}$ and $1700^{\circ} \mathrm{C}$. The tritium exposures were performed at $1400^{\circ} \mathrm{C}, 1500^{\circ} \mathrm{C}$, and $1600^{\circ} \mathrm{C}$ as a function of time using a gas pressure of 1 atmosphere. The approach to equilibrium absorption of tritium for the two different materials was also determined by outgassing samples that had been exposed to tritium gas at $1200^{\circ} \mathrm{C}$ for different times. The results for both types of experiments were compared to the earlier[2] experiments using silicon carbide vapor deposited at $1550^{\circ} \mathrm{C}$. The extensive material characterization that was performed on these materials is included as the appendix.

\section{Background}

Experimental results on the migration of tritium in silicon carbide vapor deposited at $1550^{\circ} \mathrm{C}$ were reported earlier[2]. Effective values for both the tritium diffusion coefficient and the solubility were given. It was found that silicon carbide is a very effective barrier for retaining tritium. Samples $80 \mu \mathrm{m}$ and thinner required times greater than 1 hour to obtain equilibrium loading of tritium even at temperatures as high as $1300^{\circ} \mathrm{C}$. Additionally, the tritium solubility was quite small and had a negative heat of solution. This combination 
of characteristics was interpreted to mean that the migration of tritium in silicon carbide is governed by trap controlled diffusion. Based on the activation energies for the apparent diffusivity and solubility, these traps were believed to be dangling bonds on $\mathrm{C}$ or Si atoms. Microstructural analysis of these samples had shown one side to have smaller grains than the other side. Nuclear reaction analysis results showing greater hydrogen isotope retention in the area with the small grains were interpreted to suggest that the trapping was occurring at grain boundaries. The samples tested in the present study were vapor deposited at $1400^{\circ} \mathrm{C}$ and $1700^{\circ} \mathrm{C}$. If the retention of tritium in silicon carbide is controlled by trapping at the grain boundaries, the new deposition temperatures should only have an effect on the equilibrium uptake of tritium if it changed the grain size of the material or if it changed the number of free bonds on the boundaries.

\section{Experimental Procedures}

\section{A. Materials}

The information listed in this section is an abbreviated version of the appendix. The silicon carbide specimens investigated in this study were produced by chemical vapor deposition in a fluidized bed of particles using techniques that are very similar to those used to deposit silicon carbide on the lithium-containing target particles used in the NP-

MHTGR. Hydrogen was used as the fluidizing gas in the bed rater and methyltrichlorosilane $\left(\mathrm{CH}_{3} \mathrm{SiCl}_{3}\right)$ was employed as the silicon carbide source gas. The particles used were $\mathrm{ZrO}_{2}$ that previously had been coated with pyrolytic carbon. To obtain flat specimens for study, small graphite blocks $7 \mathrm{~mm}$ by $7 \mathrm{~mm}$ by $3 \mathrm{~mm}$ were included in the fluidized bed of particles and were coated with silicon carbide along with the particles.

To prevent significant metal concentrations at the silicon carbide-carbon interface, the graphite blocks were first exposed to flowing $\mathrm{Cl}_{2}$ at $1700^{\circ} \mathrm{C}$ for 4 hours followed by heating to above $2000^{\circ} \mathrm{C}$ in hard vacuum. The blocks were then coated with an anisotropic pyrolytic carbon layer which had a very smooth "as-deposited" surface. This produced a smooth interface between the carbon and the silicon carbide resulting in a smooth surface on the silicon carbide when the carbon was removed. Deposition times were adjusted to obtain silicon carbide coating thicknesses of about $75 \mu \mathrm{m}$. After the silicon carbide coating, the edges of the blocks were cut off, and the blocks were heated in air at $8000^{\circ} \mathrm{C}$ for 12 hours to burn away all of the graphite and pyrocarbon. The resulting silicon carbide wafers were etched in $\mathrm{HF}$ to remove the small $\mathrm{SiO}_{2}$ layer that was formed during the 
graphite burning step. Production temperatures of $1400^{\circ} \mathrm{C}, 15500^{\circ} \mathrm{C}$, and $1700^{\circ} \mathrm{C}$ were used for the silicon carbide deposition step. With the exception of the samples deposited at $1400{ }^{\circ} \mathrm{C}$, all samples had densities of $3.20 \mathrm{~g} / \mathrm{cm}^{3}$ or higher. The $1400^{\circ} \mathrm{C}$ samples had recorded densities of 3.16 and $3.17 \mathrm{~g} / \mathrm{cm}^{3}$.

$1550^{\circ} \mathrm{C}$ is the temperature at which the real tritium targets will be coated with silicon carbide. For that reason, they are referred to in this report as standard production samples. The standard production samples have small grains near the substrate surface and large and columnar grains near the outer surface. The columnar grains are as big as $5 \mu \mathrm{m}$ at the base with a length of 10 to $20 \mu \mathrm{m}$. The smaller grains near the substrate have an average length closer to $1 \mu \mathrm{m}$. The silicon carbide vapor deposited at $1700^{\circ} \mathrm{C}$ is similar to the standard production material with the exception that the columnar grains are larger. Some of the grains are 10 to $15 \mu \mathrm{m}$ at the base with lengths of 20 to $40 \mu \mathrm{m}$. The grains near the substrate appear to be very similar to that for the standard production silicon carbide. The silicon carbide deposited at $1400^{\circ} \mathrm{C}$ appeared to have a small amount of porosity. This is consistent with the density measurements. The porosity does not appear to be connected and should not have any real effect on the tritium migration. The grain structure of this material was significantly different from the other two types. There were no columnar grains present. The grains were consistently 0.5 to $1 \mu \mathrm{m}$ in length and equiaxed.

\section{B. Procedures}

Tritium retention measurements were performed by exposing the silicon carbide samples to deuterium/tritium gas at elevated temperatures and then outgassing them is a separate system. The samples were exposed to the gas in the high temperature tube furnace shown schematically in Figure 1. The gas consisted of $99 \%$ deuterium and $1 \%$ tritium. The gas pressure was maintained at 1 atmosphere by the use of an Edward's flow control system. A small flow of several cc/minute was used to keep a fresh supply of gas and minimize impurity buildup during the experiment.

The retention measurements were performed for temperatures $1400^{\circ} \mathrm{C}, 1500^{\circ} \mathrm{C}$, and $1600{ }^{\circ} \mathrm{C}$. An exposure time of 1 hour was used for each of the samples. From reference 1 it is known that the diffusion coefficient at $1400^{\circ} \mathrm{C}$, the lowest exposure temperature, is $2.6 \times 10^{-9} \mathrm{~cm}^{2} / \mathrm{s}$. For sample thicknesses of less than $100 \mu \mathrm{m}$ with gas entering from both sides, the 1 hour exposure time is sufficient to obtain equilibrium loading. After loading, the sample was transferred to the system shown in Figure 2. During rapid heating of the sample to $1600^{\circ} \mathrm{C}$, gas consisting of $99 \%$ helium and $1 \%$ hydrogen was swept over the sample at a rate of $250 \mathrm{cc} /$ minute and out of the system through an ionization chamber. The 


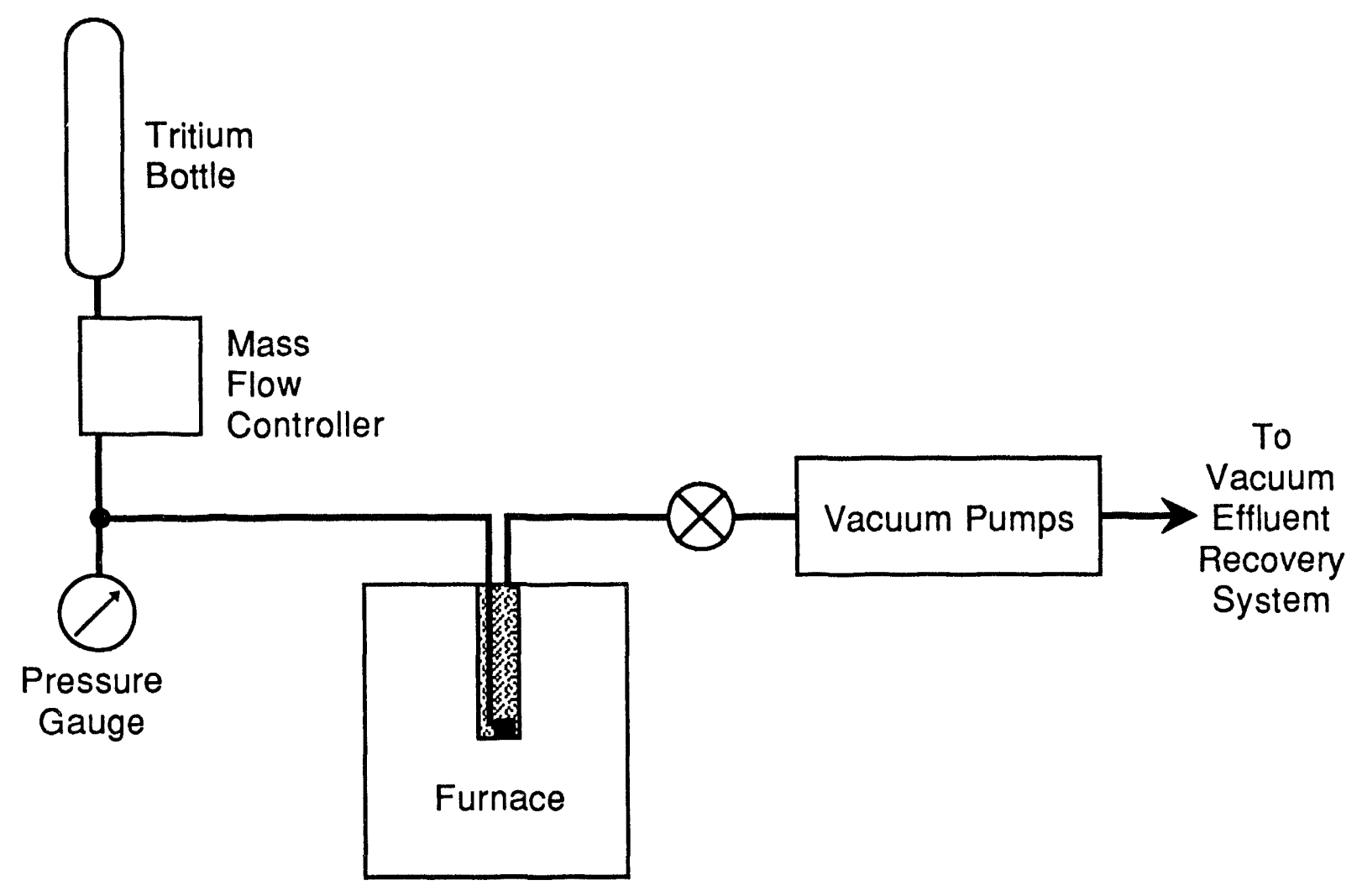

Figure 1. Tritium Exposure System 


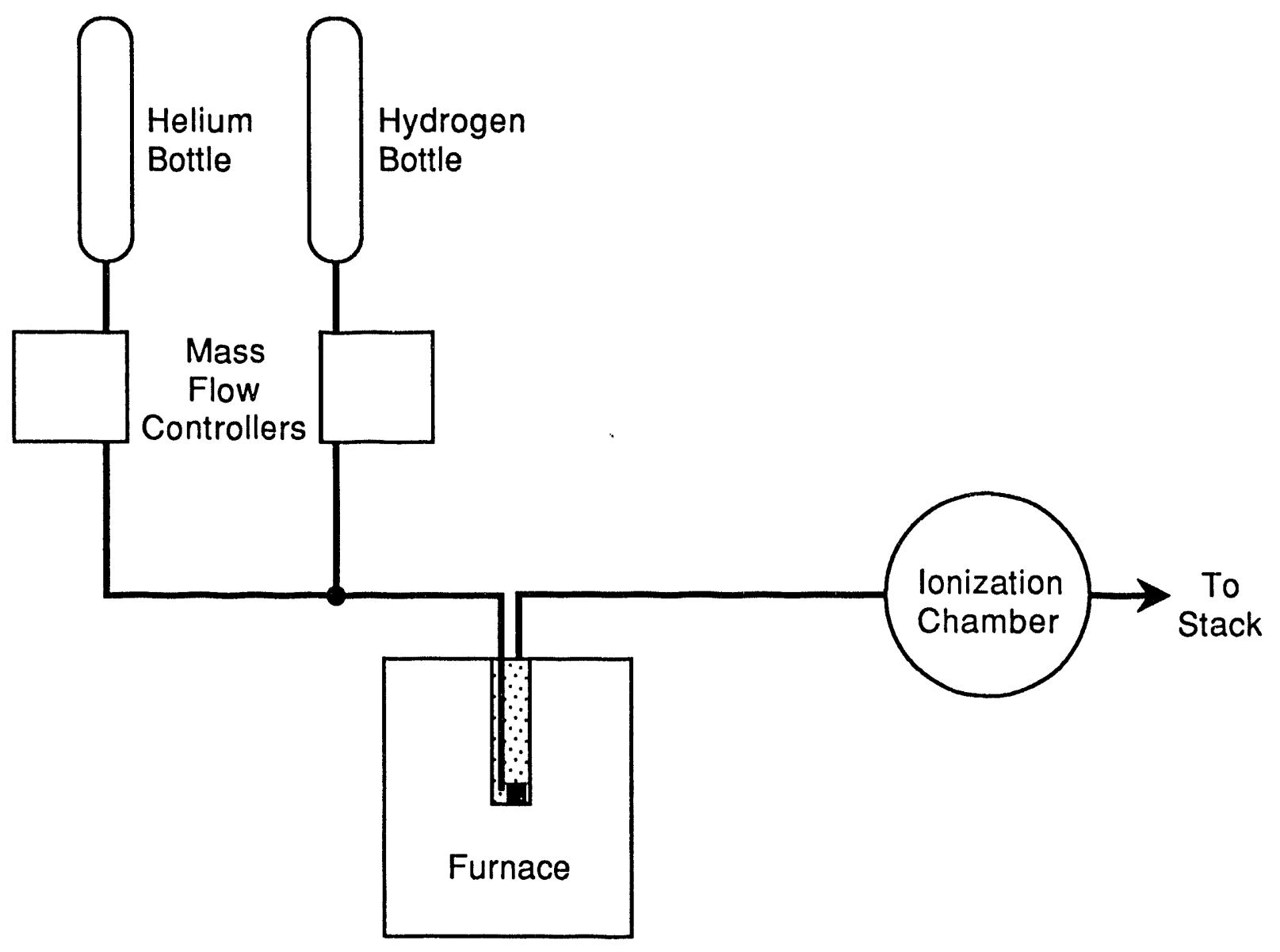

Figure 2. Tritium Thermal Desorption System 
temperature was held until the ionization chamber reading dropped to background. Because the gas used during the exposures was only $1 \%$ tritium, the data from the ionization chamber was multiplied by 100 to calculate the total hydrogen isotope retention. The above procedure was repeated for samples exposed to the tritium gas at $1200^{\circ} \mathrm{C}$. The time of exposure was varied to allow the determination of the approach to equilibrium absorption of tritium.

\section{Experimental Results}

The experimental results for the equilibrium retention of tritium in the beta silicon carbide vapor deposited at $1400^{\circ} \mathrm{C}, 1550^{\circ} \mathrm{C}$, and $1700^{\circ} \mathrm{C}$ is shown in Figure 3. The equilibrium measurements were performed at $1400{ }^{\circ} \mathrm{C}, 1500^{\circ} \mathrm{C}$, and $1600^{\circ} \mathrm{C}$. The tritium retention results for the samples vapor deposited at $1400^{\circ} \mathrm{C}$ and $1550^{\circ} \mathrm{C}$ are almost identical. The amount of retained tritium for the samples deposited at $1700^{\circ} \mathrm{C}$ is lower by abcut a factor of 3 . This reduction is understandable. It was postulated in Reference 2 that tritium migration occurs along grain boundaries where it is governed by trap controlled diffusion. This would suggest that the apparent solubility is controlled by the number of trap sites is proportional to the surface area of the grains. The larger grains of the material deposited at the higher temperature could easily have only $1 / 3$ of the grain surface area of the standard production material. It is the agreement between the results for the standard production material and that deposited at $1400^{\circ} \mathrm{C}$ that is difficult to understand. The average grain size of the silicon carbide depusited at the lower temperature is clearly smaller than the other two materials. The smaller grain size means greater grain surface area which should translate into greater equilibrium retention of tritium. There are three possible explanations for the lower than anticipated tritium retention in the material deposited at $1400^{\circ} \mathrm{C}$ :

a) The model for tritium retention and migration in silicon carbide is wrong

b) The grains of the $1400^{\circ} \mathrm{C}$ produced material have less active surface areas

c) Grain growth is occurring during the measurements

There is little doubt that the migration of tritium in silicon carbide is occurring by means of trap controlled diffusion. The reader is referred to reference 2 for a detailed discussion of the reasoning behind this model. The high value for the diffusion activation energy and the negative heat of solution for the solubility are the primary pieces of evidence on which the 


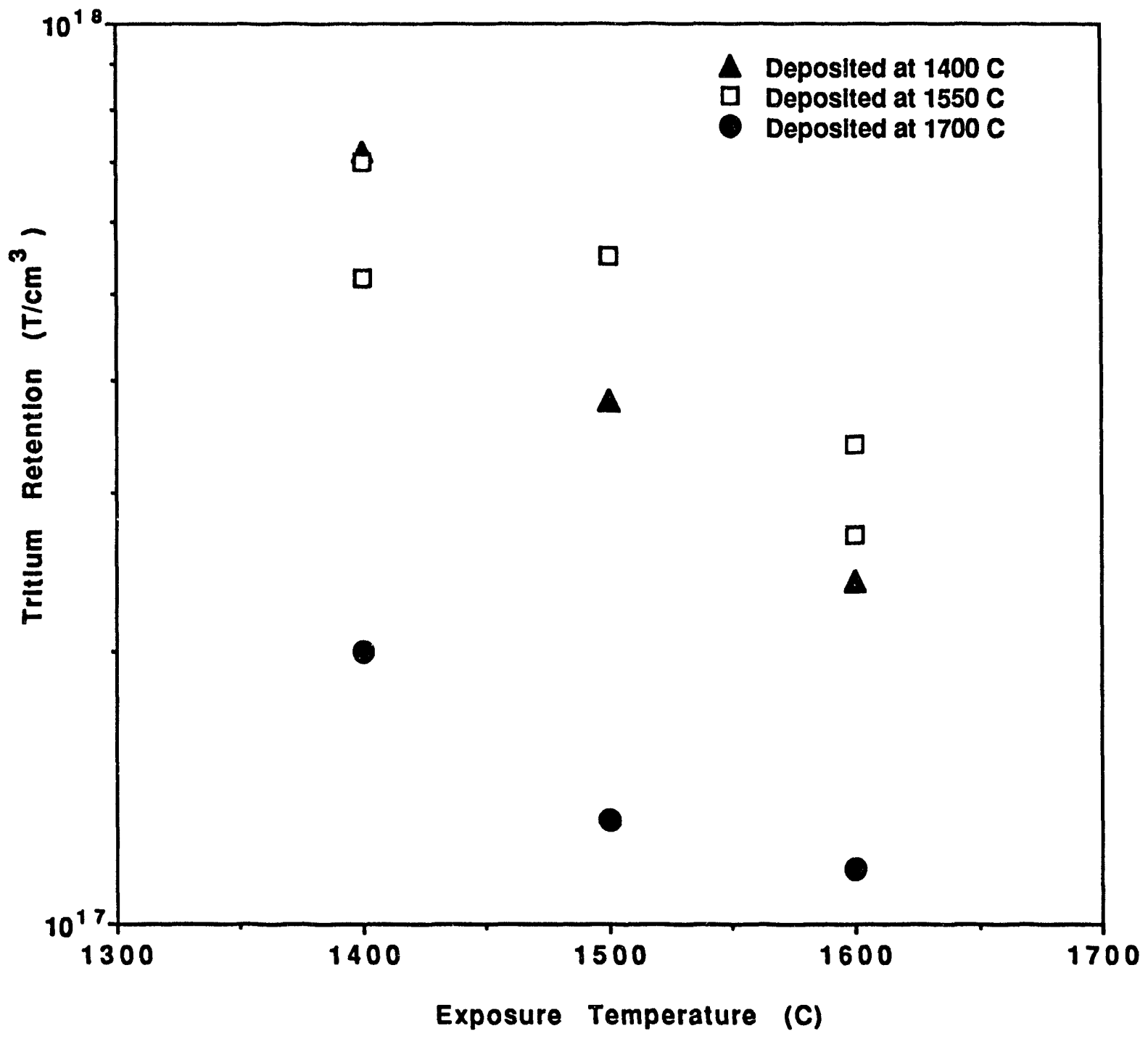

Figure 3. Effect of Vapor Deposition Temperature on the Equilibrlum Retention of Tritlum in Silicon Carbide 
model is based. The question remains whether the traps are located at the grain boundaries. There is evidence in Reference 2 showing increased deuterium located on the substrate side of the sample where the grains are smaller. This suggests trapping at the grain boundaries. There is evidence in Reference 3 by Wampler et al. that increasing the defect density in silicon carbide by radiation damage does not increase the trapping of tritium. In that study, most of the ion damage was created in an area where the grain boundary density was very low. There was almost no increase in the retention of deuterium due to the radiation damage. This finding also suggests that hydrogen isotopes do not penetrate into the grains. There appears to be sufficient evidence that the model is correct. One possibility is that the grains produced at $1400^{\circ} \mathrm{C}$ are less chemically active than those produced at the other deposition temperatures. This doesn't seem plausible. The grain growth that occurs at the higher temperatures typically involves growth on the active surfaces. The material deposited at the lower temperature should have more active surfaces. Another possibility is grain growth during the experiment. Evidence that this could be happening came in the experiments examining the approach to equilibrium. In those experiments, samples of all three materials were exposed to the tritium gas for different times at $1200^{\circ} \mathrm{C}$. The results for those experiments are shown in Figure 4. The results for the silicon carbide deposited at $1700^{\circ} \mathrm{C}$ is clearly approaching an equilibrium value lower than the other two materials. The material deposited at $1400^{\circ} \mathrm{C}$ also clearly appears to be approaching an equilibrium value above the material deposited at $1550^{\circ} \mathrm{C}$. These results appear to suggest that something occurs in the material deposited at $1400^{\circ} \mathrm{C}$ when it is heated to temperatures equal to or greater than its deposition temperature.

Regardless of the cause of the less than expected retention of tritium in the silicon carbide vapor deposited at $1400^{\circ} \mathrm{C}$, the important conclusion of this experimental work is that the deposition temperature of the silicon carbide will have almost no effect on the ability of the microspheres to contain the tritium. The decrease in the equilibrium retention of tritium for the samples deposited at $1700^{\circ} \mathrm{C}$ should not affect the steady state release of tritium from the microspheres. For trap controlled permeation, a decrease in trap density is offset by an increase in the migration rate due to an increase in the effective jump distance between traps. The net effect is no change in tritium release rates.

\section{Conclusion}

Silicon carbide samples vapor deposited at $1400^{\circ} \mathrm{C}, 1550^{\circ} \mathrm{C}$, and $1700^{\circ} \mathrm{C}$ all have very similar tritium migration characteristics. Experimental results on the approach to 


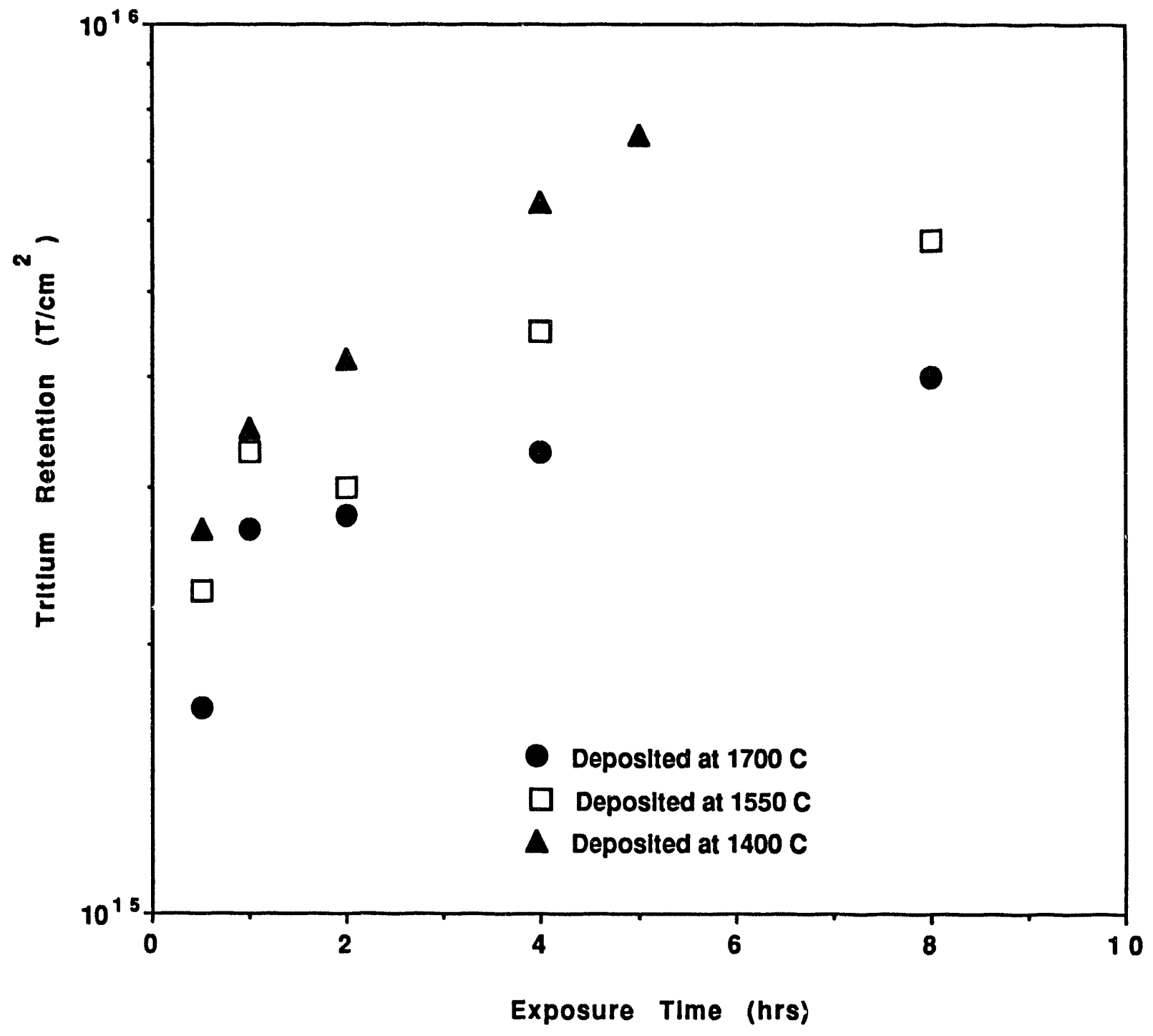

Figure 4. Effect of Vapor Deposition on the Retentlon of Tritium In Sillcon Carbide at $1200 \mathrm{C}$ as a Function of Time 
equilibrium absorption of tritium at $1200^{\circ} \mathrm{C}$ followed similar patterns for all three materials. The amount of tritium retained at equilibrium was almost identical for the samples produced at $1400^{\circ} \mathrm{C}$ and $1550^{\circ} \mathrm{C}$. The tritium retained in the $1700^{\circ} \mathrm{C}$ deposited silicon carbide was a factor of 3 less than the other two materials. These results suggest that variations in the deposition temperature of real tritium target for the NPR-MHTGR program will not affect the ability of the microspheres to retain their produced tritium.

\section{References}

1. R.A. Causey, "Research Plan for Small-Scale Laboratory Experiments on the Behavior of Tritium in the NPR-MHTGR Tritium Target Materials," SAND918208, February 1991.

2. R.A. Causey, W.R. Wampler, J.R. Retelle, and J.L. Kaae, "Tritium Migration in Vapor Deposited Beta Silicon Carbide," in press, J. Nucl. Mater., SAND92-8217, September 1992.

3. W.R. Wampler and R.A. Causey, "Influence of Lattice Damage c $\urcorner$ Retention and Transport of deuterium in Beta Silicon Carbide," to be published in J. Nucl. Mater. and as a SAND Report. 


\section{APPENDIX}

Characterization of Silicon Carbide Samples

Performed at General Atomics by J. L. Kaae 


\section{EXPERIMENTAL}

The silicon carbide specimens investigated in this study were produced by chemical vapor deposition in a fluidized bed of particles using techniques that are very similar to those used to deposit silicon carbide on the lithium-containing target particles used in the NP-MHTGR.

The fluidized bed coater used for this study is shown schematically in Fig. 1. Hydrogen was employed as the fluidizing gas, and methyltrichlorosilane $\left(\mathrm{CH}_{3} \mathrm{SiCl}_{3}\right)$ was employed as the silicon carbide source gas. A new $6.35 \mathrm{~cm}$ diameter graphite tube was used for each coating run. The particles employed were $\mathrm{ZrO}_{2}$ that previously had been coated with pyrolytic carbon. The average size of these nearly spherical particles was about $750 \mu \mathrm{m}$, and a charge of $100 \mathrm{gm}$ was utilized for each coating run. A hydrogen flow of $23.51 / \mathrm{min}$, as measured at room temperature and ambient pressure, was used in every case, and the $\mathrm{CH}_{3} \mathrm{SiCl}_{3}$ flow was adjusted for each type of silicon carbide to obtain a specified deposition rate.

In order to obtain flat specimens for study, small graphite blocks $0.7 \mathrm{~cm} \times 0.7 \mathrm{~cm} \times 0.3 \mathrm{~cm}$, were included in the fluidized bed of particles and were coated with silicon carbide along with the particles. Before silicon carbide coating, the blocks were first coated with an anisotropic pyrolytic carbon layer which had a very smooth as-deposited surface; this produced a smooth interface between the carbon and the silicon carbide and thereby a smooth surface on the silicon carbide when the carbon was removed. Deposition times were adjusted to obtain silicon carbide coating thicknesses of about $75 \mu \mathrm{m}$. Subsequent to silicon carbide coating, the edges of the coated blocks were cut off, and the blocks were heated in air at $800^{\circ} \mathrm{C}$ for 12 hours which sufficed to burn away all of the graphite and pyrocarbon. Then, the resulting silicon carbide wafers were etched in $\mathrm{HF}$ to remove the small $\mathrm{SiO}_{2}$ layer that 


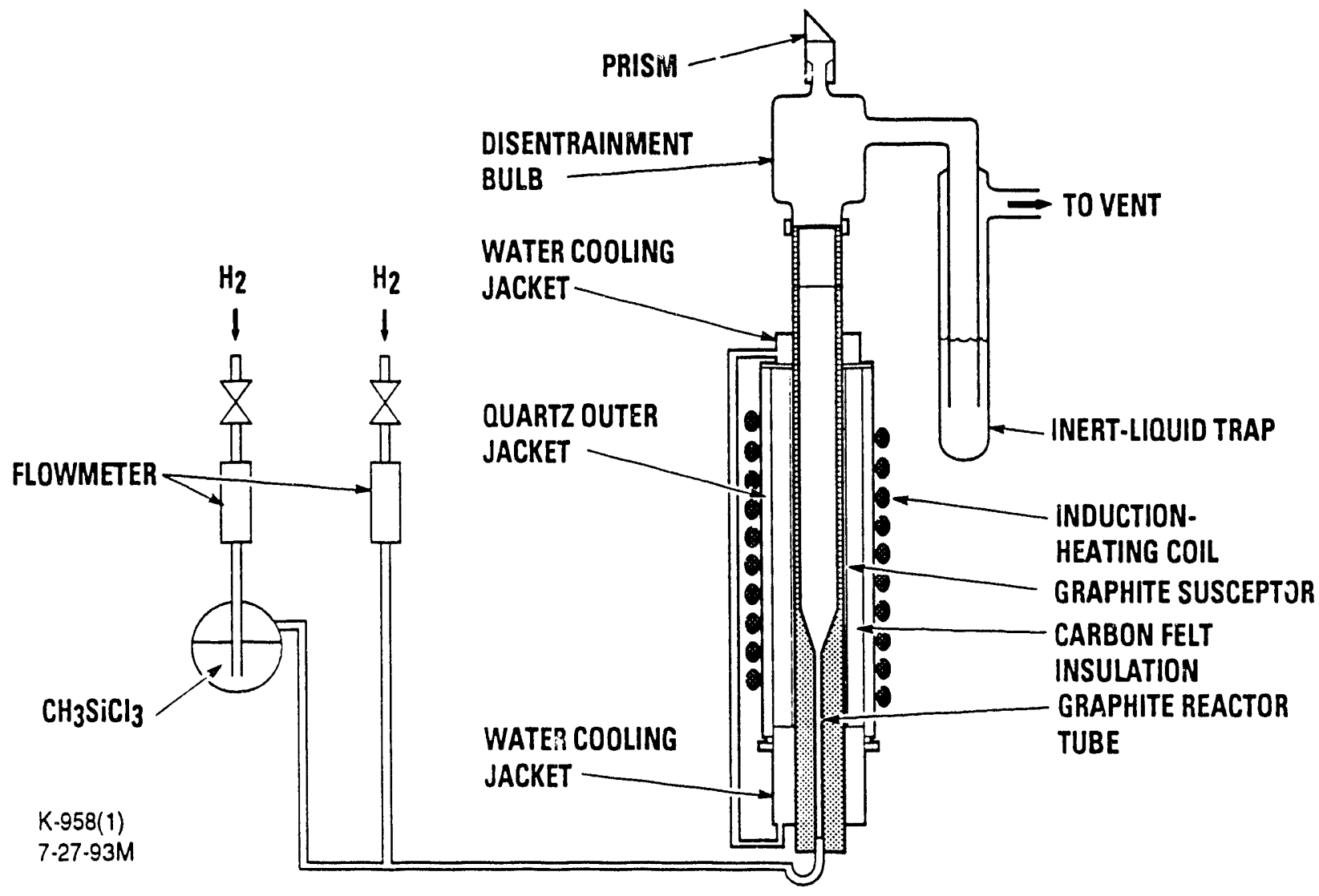

Fig. 1 A schematic drawing of the fluidized-bed chemical-vapordeposition apparatus used in this study. 
was formed during the graphite burning step. These specimens were used for tritium migration studies.

It was found that it was necessary to purify the graphite blocks before coating because without the purifying treatment, the inside surfaces of the silicon carbide coatings became decorated with particles containing metals such as vanadium and iron. (silicon carbide has a high affinity for many metals, and trace concentrations of metals in the graphite resulted in significant metal concentrations at the silicon carbide-carbon interface.) In a treatment that was perhaps more extreme than necessary to remove the metal impurities, the graphite blocks were first exposed to flowing $\mathrm{Cl}_{2}$ at $1700^{\circ} \mathrm{C}$ for 4 hours, and then they were then heated to above $2000^{\circ} \mathrm{C}$ in a hard vacuum.

The density of one silicon carbide specimen from each coating run was measured in a mixture of methyliodide and acetone using a sinkfloat technique wherein a density gradient was established in a column by mixing the two liquids so that a concentration gradient of one in the other was produced. The density gradient in the liquid column was calibrated with samples of known density. Then, the densities of the silicon carbide specimens were determined by the positions where they remained suspended in the column.

$x$-ray diffraction measurements on specimens from each siIicon carbide type were made using two techniques. First, diffractometer scans were made using a graphite monochrometer to select only the diffraction peaks produced by copper $\mathrm{K} \alpha$ radiation. These measurements were used to identify the phases present from the positions and intensities of the diffraction peaks. Then, samples were oriented at appropriate angles for diffraction from selected planes in a Debye-Scherrer camera, and diffraction intensities from copper $\mathrm{K} \alpha$ irradiation were recorded on film. Comparisons of the variations of the intensity of the diffraction lines with distance 
from the horizontal line of symmetry allowed qualitative measurement of the preferred orientation of the selected planes parallel to the deposition plane of the specimens.

Selected specimens were polished and etched followed by examination using optical and scanning electron microscopy. Etching was carried out either electrolytically in an aqueous solution of $\mathrm{H}_{2} \mathrm{C}_{2} \mathrm{O}_{4}$ (1) or in a molten eutectic mixture of $\mathrm{K}_{2} \mathrm{CO}_{3}$ and $\mathrm{NaF}$ (2) or in a boiling mixture of aqueous saturated solutions of $\mathrm{NaOH}$ and $\mathrm{K}_{3} \mathrm{Fe}(\mathrm{CN})_{6}(3)$.

Transmission electron microscopy was carried out on specimens that had been thinned by argon ion bombardment after initiai thinning by mechanical polishing. 


\section{RESULTS}

\section{Deposition and Density}

Silicon carbides deposited at three different temperatures were investigated in this study. The nominal deposition temperatures (the temperatures of the wall of the graphite coater tube in the middle of the hot zone), and typical $\mathrm{CH}_{3} \mathrm{SiCl}_{3}$ feed rates, average deposition rates and densities of these three different silicon carbides are shown in Table 1. The deposition conditions of the three types of silicon carbide differed primarily in the deposition temperature although Type A was deposited at a somewhat higher rate than Types $B$ and $C$. The indicated densities of Type $A$ and $B$ are slightly higher than the theoretical density for $B$ silicon carbide which is $3.217 \mathrm{~g} / \mathrm{cm}^{3}$. The discrepancy of the measured value being larger than the theoretical value almost certainly results from experimental error in aetermining the third place after the decimal. Thus, Types $A$ and $B$ can be taken to be completely or very nearly theoretically dense. The density of Type $C$ silicon carbide is lower at $3.17 \mathrm{~g} / \mathrm{cm}^{3}$. 
TABLE 1

NOMINAL DEPOSITION TEMPERATURES, $\mathrm{CH}_{3} \mathrm{SiCl}_{3}$ FEED RATES, AVERAGE DEPOSITION RATES AND DENSITIES OF THE SILICON CARBIDES INVESTIGATED IN THIS STUDY

\begin{tabular}{||c|c|c|c|c||}
\hline TYPE & $\begin{array}{c}\text { NOMINAL } \\
\text { DEPOSITION } \\
\text { TEMPERATURE }\left({ }^{\circ} \mathrm{C}\right)\end{array}$ & $\begin{array}{c}\mathrm{CH}_{3} \mathrm{SiCl}_{3} \\
\text { FEED RATE } \\
(\mathrm{g} / \mathrm{min})\end{array}$ & $\begin{array}{c}\text { AVERAGE } \\
\text { DEPOSITION RATE } \\
(\mu \mathrm{m} / \mathrm{min})\end{array}$ & $\begin{array}{c}\text { DENSITY } \\
\left(\mathrm{g} / \mathrm{cm}^{3}\right)\end{array}$ \\
\hline $\mathrm{A}$ & 1700 & 3.25 & 0.35 & 3.22 \\
\hline $\mathrm{B}$ & 1550 & 1.55 & 0.20 & 3.22 \\
\hline $\mathrm{C}$ & 1400 & 1.00 & 0.20 & 3.17 \\
\hline
\end{tabular}




\section{$\underline{X-R a y ~ D i f f r a c t i o n ~}$}

The first five $x$-ray diffraction peaks observed during a diffractometer scan of one of the silicon carbides is shown in Fig. 2 . The diffraction peaks in this figure correspond to diffraction from the $\{111\},\{200\},\{220\},\{311\}$ and $\{222\}$ planes of the $B$ (cubic) form of silicon carbide. Additional diffraction peaks from $B$ silicon carbide higher order planes were observed at larger diffraction angles. The other two silicon carbides also had diffraction peaks at these same $B$ silicon carbide diffraction angles.

Because the observation of x-ray diffraction peaks that were attributed to the presence of second-phase silicon or graphite has been reported for silicon carbides deposited under conditions similar to those used in this study (4), the diffractometer scans were carefully examined for peaks that could have been produced by these phases. None were observed.

Since absorption is significant when carrying out $x$-ray diffraction measurements on silicon carbide specimens $75 \mu \mathrm{m}$ thick, the $x$-rays do not sample the whole thickness of the specimens used in this study. This is especially true for the important low-angle reflections. For this reason, measurements were made with the $x$-ray beam impinging first on the substrate side and then on the outer surface side of each specimen. While the diffraction angles of the first ten diffraction peaks were always the same, the intensities of the diffraction peaks differed from one type of silicon carbide to another and for two of the silicon carbide types from one side of a specimen to the other. These intensities normalized to the intensity of the $\{111\}$ peak are listed in Table 2 for each side of the three silicon carbide types along with the intensities reported for diffraction from the $B$ form of this material in the JCPDS Power Diffraction File (5). 


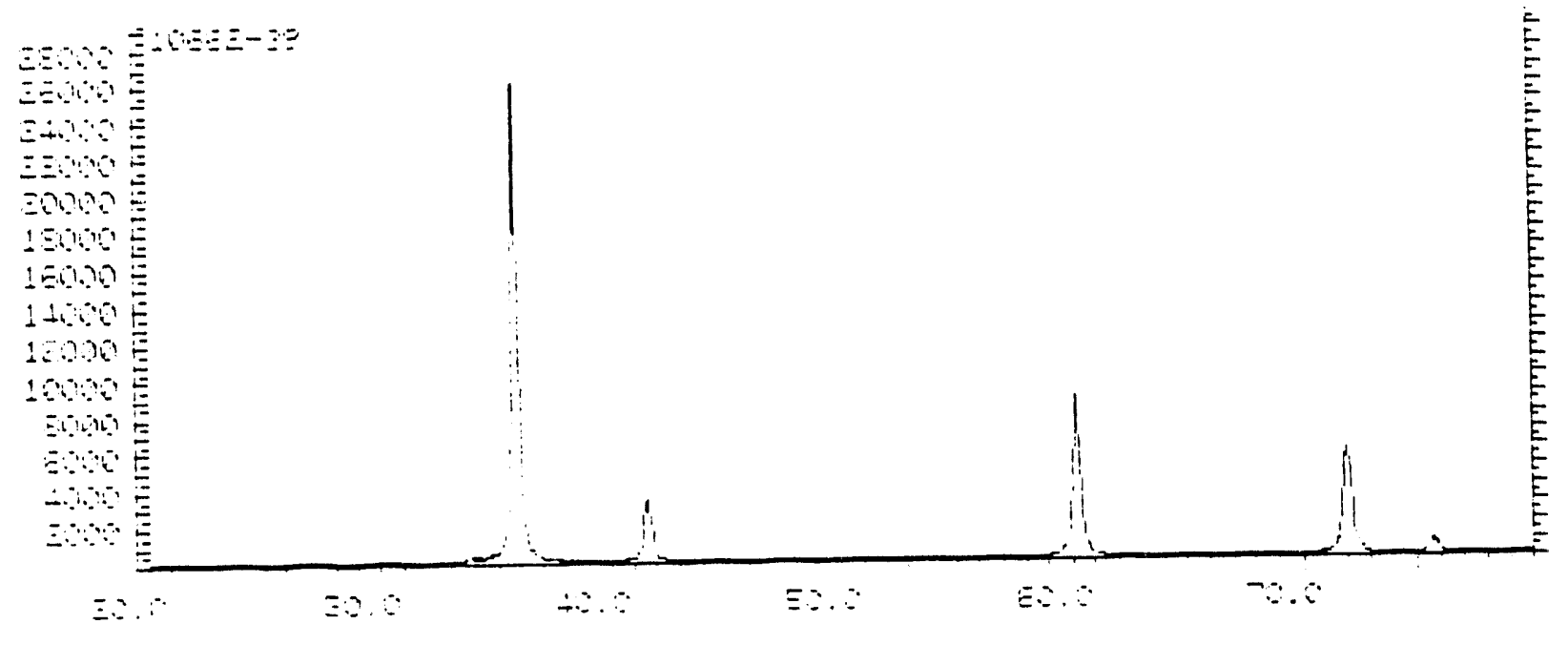

Fig. 2 The first five x-ray diffraction peaks observed during a diffractometer scan of one of the silicon carbide samples. In order of increasing diffraction angle, the peaks were produced by diffraction from the $\{111\},\{200\},\{311\},\{222\}$ and $\{400\}$ planes of beta silicon carbide. 
TABLE 2

\begin{abstract}
COMPARISON OF THE INTENSITIES OF THE FIRST TEN X-RAY DIFFRACTION PEAKS OF THE THREE TYPES OF SILICON CARBIDE WITH THOSE REPORTED FOR B SILICON CARBIDE IN THE JCPDS POWER DIFFRACTION FILE
\end{abstract}

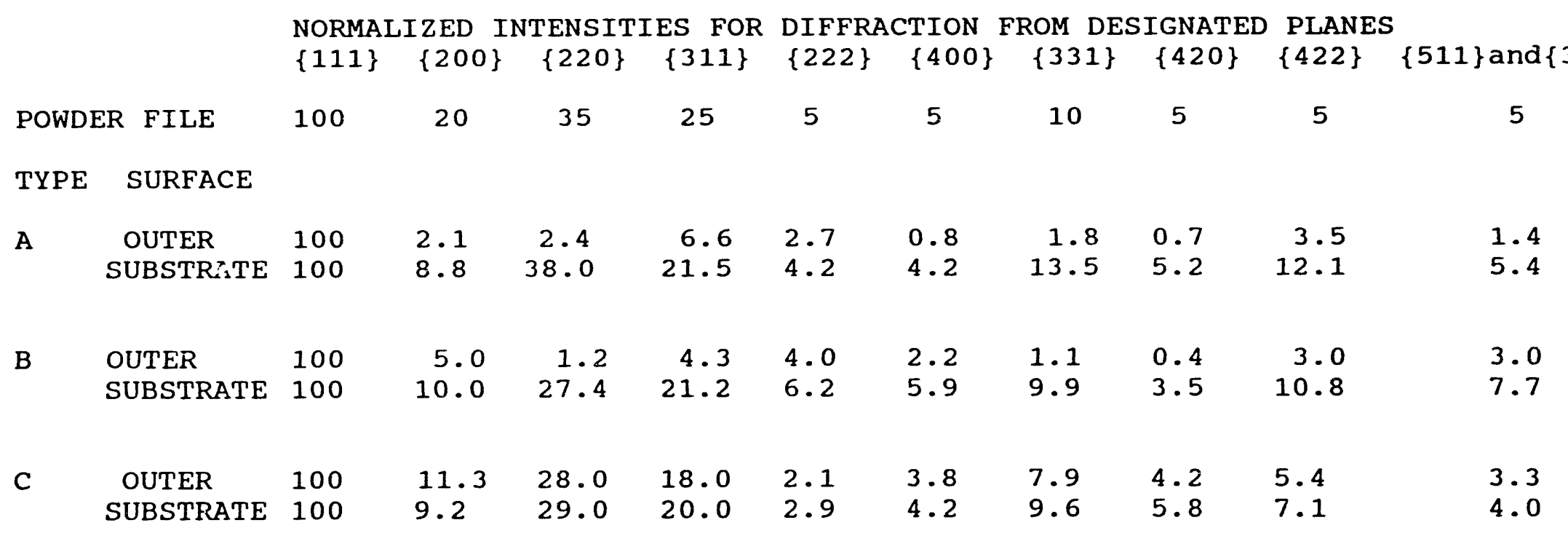


Why do the diffraction peak intensities differ from one type of silicon carbide to another type of silicon carbide, from one side of a specimen to the other side of a specimen, and from those reported in the Powder Diffraction File? Several explanations of these intensity variations are possible:

1. A large grain size may lead to poor sampling of all crystal orientations

2. Stacking faults may cause lowering of the intensities of certain diffraction peaks.

3. There may be preferred orientations of the grains in the silicon carbide.

The $x$-ray beam was large compared to the grain sizes of these silicon carbides. Therefore, the first explanation is not likely to be the reason for the differing diffraction intensities.

Chin, Gantzel and Hudson have described how the disorder produced by stacking faults on $B$ silicon carbide $\{111\}$ planes reduces the diffraction intensity of the $\{200\},\{400\}$ and $\{331\}$ peaks relative to the $\{111\}$ peak $(6)$. (Stacking faults on $\{111\}$ planes are common in B silicon carbide (7).) This effect is expected to be especially apparent in the intensity of the $\{200\}$ peak, primarily because it normally is a relatively high-intensity peak. The diffraction patterns observed for the substrate-surface reflections of the Type A and the Type B silicon carbides and for both the outer-surface and the substrate-surface reflections of the Type $C$ silicon carbide are readily explained by the presence of stacking faults on $\{111\}$ planes. In these cases the normalized $\{200\}$ peak intensities are low relative to that of the powder File, but the other normalized peak intensities are similar to those of the Powder File. 
Stacking faults, however, cannot explain the reduced intensities of the outer-surface diffraction peaks for the Type $A$ and Type $B$ silicon carbides where with the exception of the $\{111\}$ peak, the intensities of all of the peaks are suppressed relative to those of the Powder File. Only preferred orientation of the $\{111\}$ planes parallel to the deposition plane can produce this overall suppression of the diffraction peak intensities.

In order to understand the method used to obtain qualitative measurements of preferred orientation in the silicon carbides, consider a single silicon carbide crystal with its surface parallel to a vertical line but inclined to a horizontal x-ray beam. When any one of the set of $\{111\}$ planes is parallel to the surface upon which the $x$-ray beam is impinging and the surface is inclined at the proper angle for $\{111\}$ diffraction $\left(17.8^{\circ}\right.$ for copper $\mathrm{K} \alpha$ irradiation), a diffracted beam will be projected on a horizontal line passing through the spot formed by the impinging beam. similarly, when any one of the set of $\{100\}$ planes is parallel to the surface upon which the $x$-ray beam is impinging and the surface is inclined at the proper angle for $\{200\}$ diffraction $\left(20.7^{\circ}\right.$ for copper $\mathrm{K} \alpha$ irradiation), a diffracted beam will be projected on the same horizontal line at a slightly greater distance from the central beam. When a collection of randomly oriented crystals replaces the single crystal, the diffracted beam of the single crystal becomes a cone of beams that is uniform in intensity all the way around the cone. However, when there is preferred orientation of a set of planes parallel to the surface and the inclination angle is the diffraction angle for that set of planes, the intensity becomes non-uniform with a maximum on the horizontal line. In this study, both the $\{111\}$ and $\{200\}$ planes were sampled qualitatively using a single inclination angle intermediate between their diffraction angles. The strip of film in the Debye-Scherrer camera sampled only part of the cone of beams, but this was sufficient to reveal preferred orientation when it was present as is shown in Figs. 3 and 4 . In Fig. 3 diffraction from the 


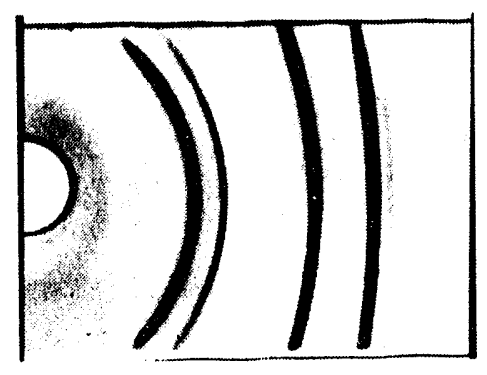

Fig. 3 The $x$-ray diffraction lines recorded from the substrate side of the Type $C$ silicon carbide in a Debye-scherrer camera. The sample surface was inclined at $20^{\circ}$ to the $x-$ ray beam, which is intermediate between the angles for diffraction from the $\{111\}$ and $\{200\}$ planes. The uniform intensities in the two segments of the diffraction rings nearest the hole for the beam indicate that there is no preferred orientation of these planes in this region of this silicon carbide. 


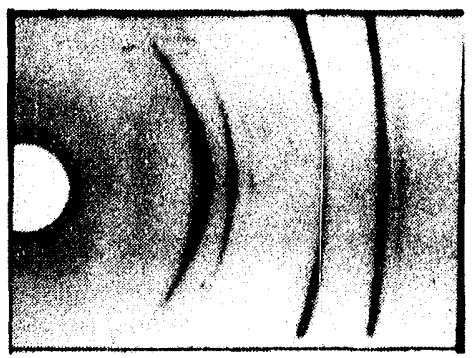

Fig. 4 The x-ray diffraction lines recorded from the outer surface side of the Type A silicon carbide in a Debye-Scherrer camera. The sample surface was inclined at $20^{\circ}$ to the $x-$ ray beam, which is intermediate between the angles for diffraction from the $\{111\}$ and the $\{200\}$ planes. The nonuniform intensities in the two segments of the diffraction rings nearest to the hole for the beam indicates that these planes are preferentially oriented parallel to the surface in this region of this silicon carbide. 
substrate side of the Type C silicon carbide produced uniform intensity in the $\{111\}$ and $\{200\}$ diffraction lines independent of the distance from the horizontal line indicating that the region near the substrate surface of the Type $C$ silicon carbide does not have preferred orientation of the $\{111\}$ and $\{100\}$ planes parallel to the surface. On the other hand, diffraction from the outer surface side of the Type A silicon carbide produced high-intensity regions of the $\{111\}$ and $\{200\}$ diffraction lines on a horizontal line through the central beam. (See Fig. 4.) Thus, there is preferred orientation of both the $\{111\}$ and $\{100\}$ planes parallel to the surface near the outer surface of this silicon carbide.

Observations of the extent of $\{111\}$ and $\{100\}$ preferred orientation near the substrate and outer surfaces of the silicon carbides made using diffraction lines recorded in the manner described above are listed in Table 3. All three types showed no preferred orientation near the substrate surface; Type $C$ also showed no preferred orientation near the outer surface. However, Type A showed strong \{111\} preferred orientation and weak $\{100\}$ preferred orientation near the outer surface, and Type $B$ showed strong preferred orientation of the $\{111\}$ set of planes and moderate preferred orientation of the $\{100\}$ set of planes near the outer surface. 
TABLE 3

QUALITATIVE OBSERVATIONS OF THE EXTENT OF PREFERRED ORIENTATION PARALLEL TO THE SURFACE

\begin{tabular}{|c|c|c|c|}
\hline TYPE & SURFACE & $\{111\}$ PLANES & $\{100\}$ PLANES \\
\hline A & $\begin{array}{c}\text { OUTER } \\
\text { SUBSTRATE } \\
\end{array}$ & $\begin{array}{c}\text { STRONG } \\
\text { NONE }\end{array}$ & $\begin{array}{l}\text { WEAK } \\
\text { NONE }\end{array}$ \\
\hline B & $\begin{array}{c}\text { OUTER } \\
\text { SUBSTRATE }\end{array}$ & $\begin{array}{l}\text { STRONG } \\
\text { NONE }\end{array}$ & $\begin{array}{c}\text { MODERATE } \\
\text { NONE }\end{array}$ \\
\hline C & $\begin{array}{c}\text { OUTER } \\
\text { SUBSTRATE }\end{array}$ & $\begin{array}{l}\text { NONE } \\
\text { NONE }\end{array}$ & $\begin{array}{l}\text { NONE } \\
\text { NONE }\end{array}$ \\
\hline
\end{tabular}




\section{Microstructures}

Type A silicon Carbide

An optical micrograph of a polished cross section of the Type A silicon carbides is shown in Fig. 5. There is little evident porosity as would be expected from the high density of this material. As further proof of the lack of porosity in this silicon carbide, a scanning electron micrograph of the same specimen is shown in Fig. 6. Again, no porosity is evident, even at the higher resolution of the scanning electron microscope.

An optical micrograph of an electrolytically etched cross section of the Type A silicon carbides is shown in Fig. 7. Although the etch is not particularly discriminating, it is obvious that the grain size is small near the substrate surface, and the grains become increasingly large and columnar with increasing distance from the substrate surface.

A scanning electron micrograph of a molten-salt-etched cross section of the Type A silicon carbide is shown in Fig. 8 . The microstructure is much better delineated in this micrograph than in the optical micrograph of the electrolytically etched cross section, but the microstructural features remain the same, namely there are small grains near the substrate surface and larger columnar-shaped grains away from the substrate surface.

Transmission electron micrographs of regions near mid-thickness of the Type A silicon carbide are shown in Figs. 9 and 10. In Fig. 9, the viewing direction is perpendicular to the deposition plane, and in Fig. 10 the viewing direction is parallel to the deposition plane. The striking features in Fig. 9 are the fringes produced by stacking faults that are inclined to the electron beam. In Fig. 10, the stacking faults are nearly parallel to the electron beam so 

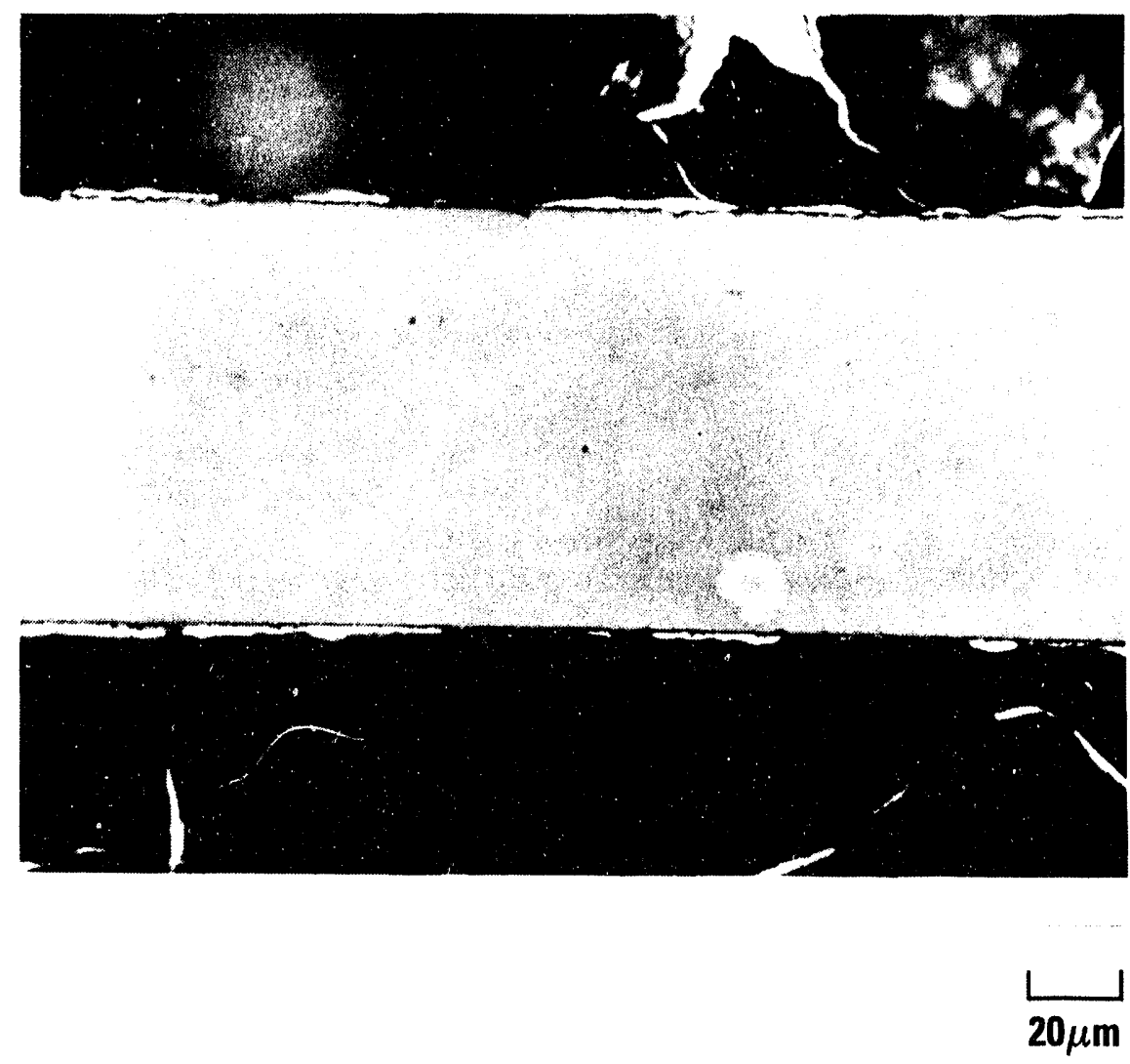

Fig.5 An optical micrograph of a polished cross section of the Type A silicon carbide. The substrates surface is at the bottom. There is little evident porosity. 


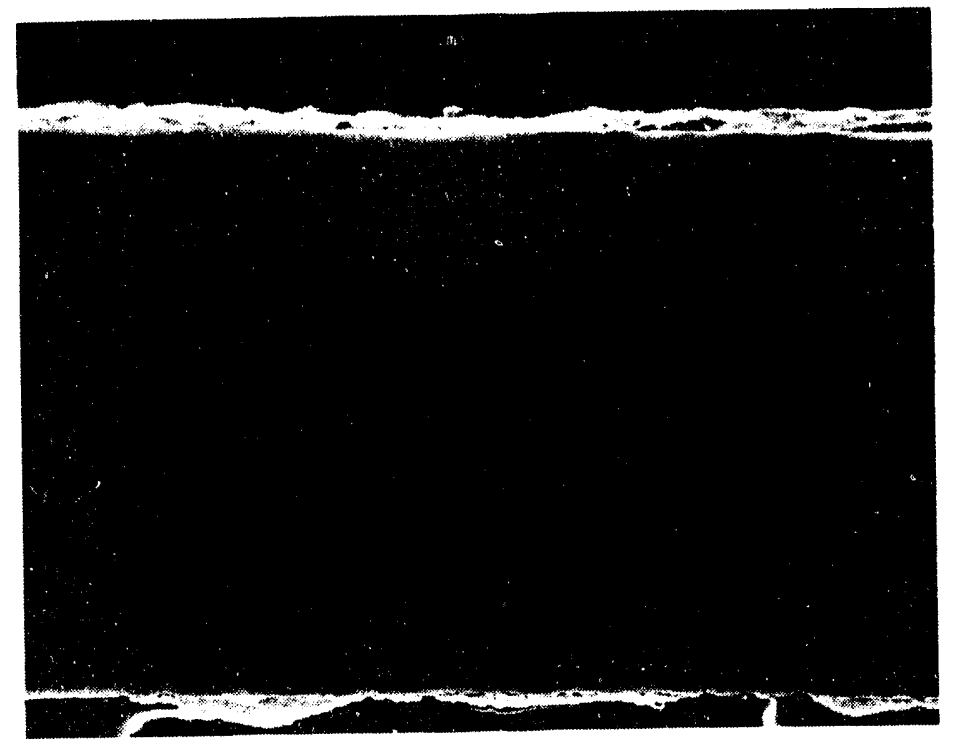

Fig. 6 A scanning electron micrograph of a polished cross section of the Type A silicon carbide. The substrate surface is at the bottom. There is little evident porosity. 

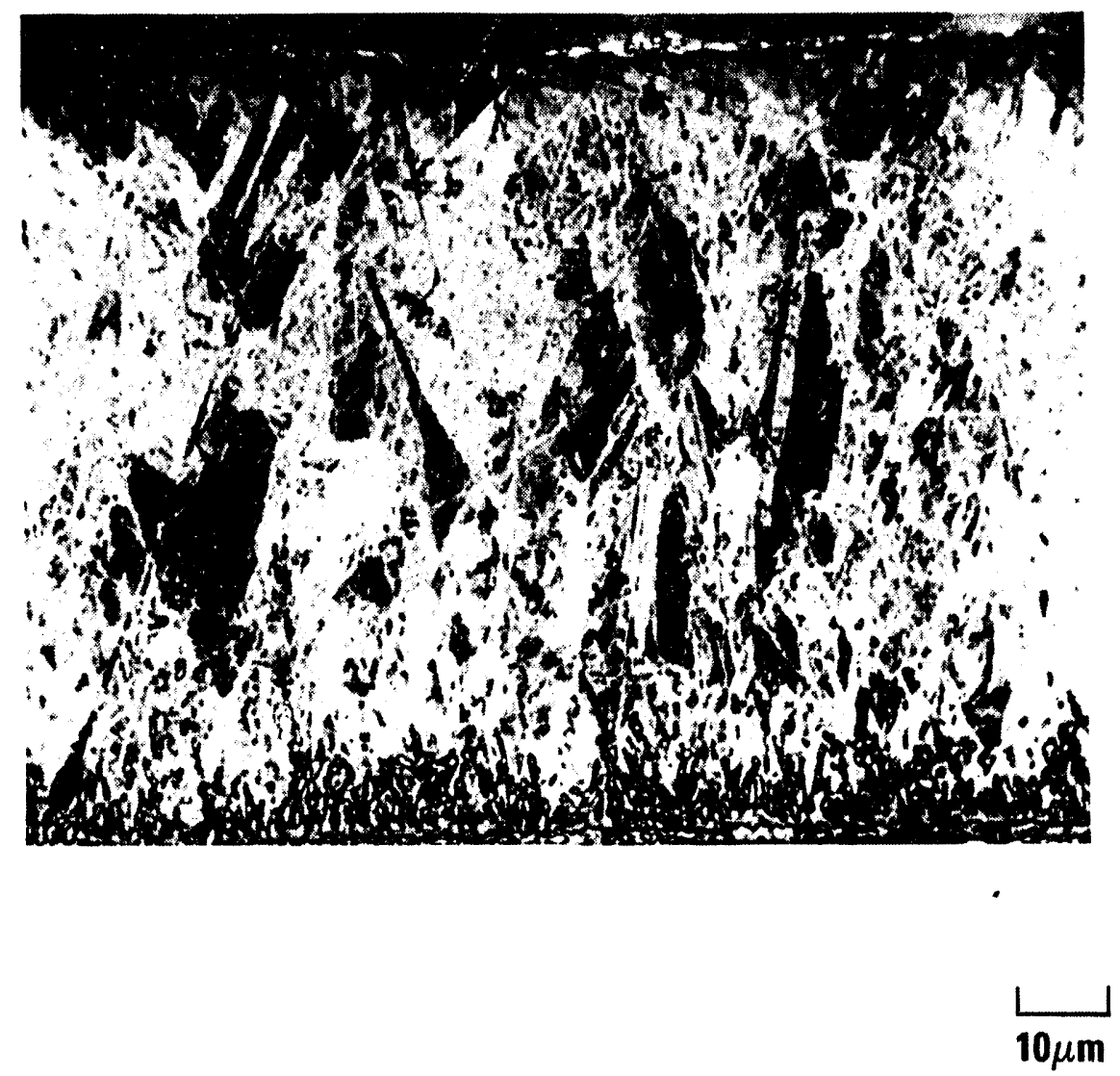

Fig. 7 An optical micrograph of an electrolytically etched cross section of the Type A silicon carbide. The substrate surface is at the bottom. The grain size is smaller near the substrate surface than near the outer surface. 


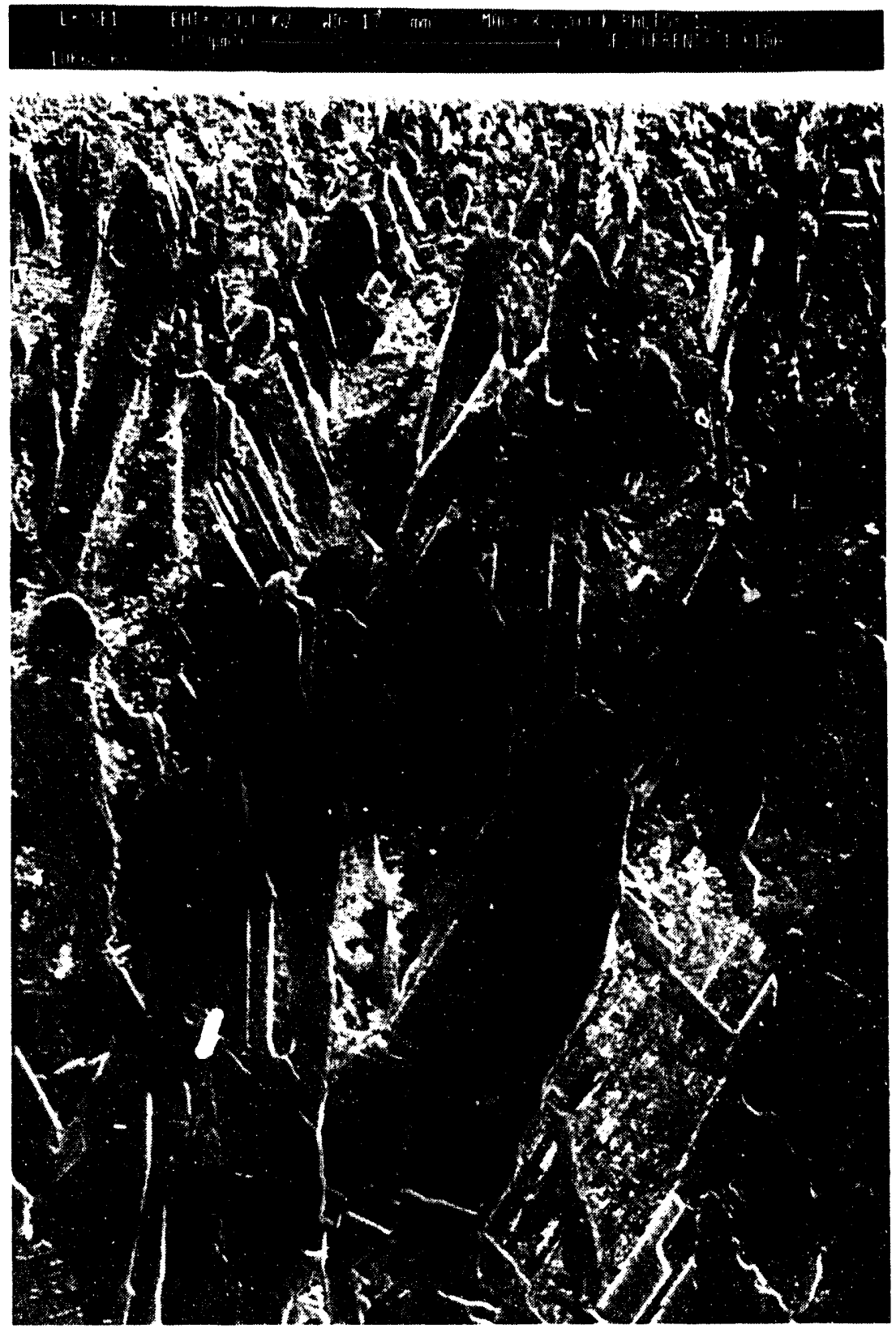

Fig. 8 A scanning electron micrograph of a molten-salt-etched cross section of the Type A silicon carbide. The substrate surface is at the top. The microstructural features are better delineated than with optical microscopy. 


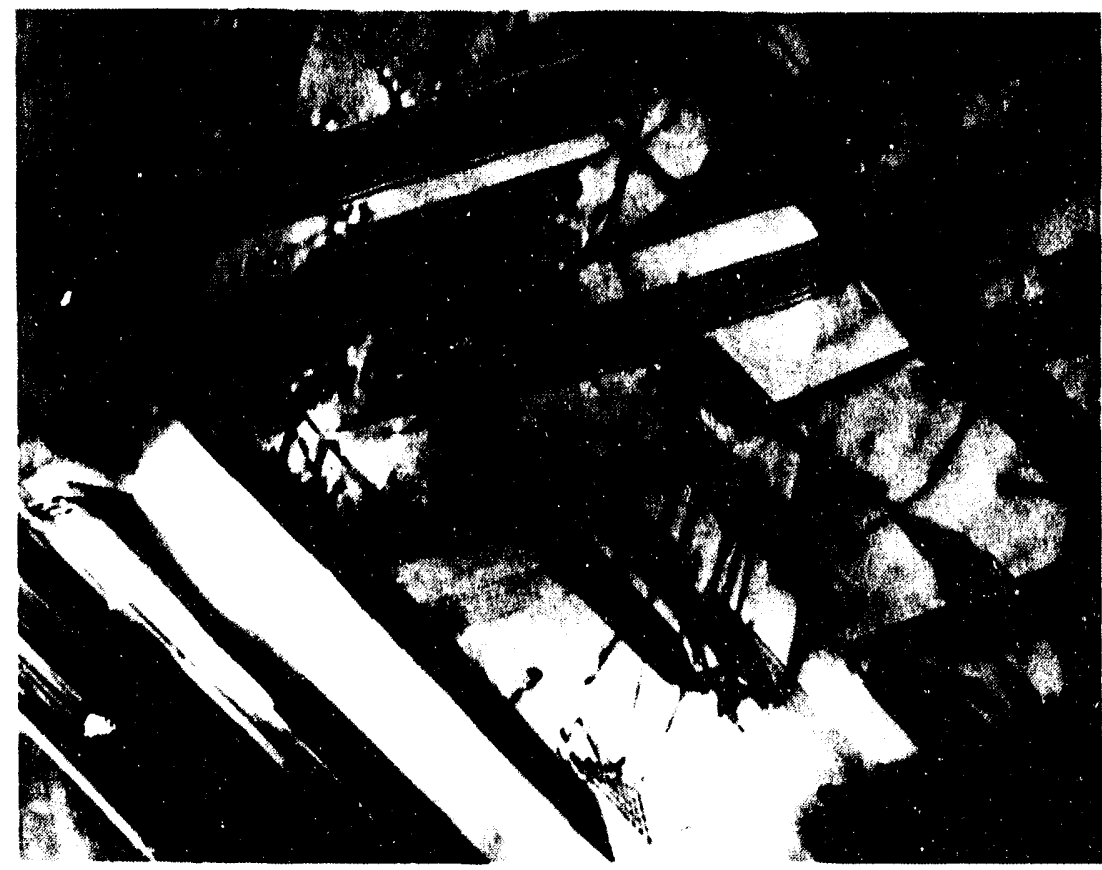

$0.25 \mu \mathrm{m}$

Fig. 9 A transmission electron micrograph of a region near midthickness of the Type A silicon carbide. The viewing direction is perpendicular to the deposition plane. Fringes produced by stacking faults on \{111\} planes are evident as are numerous dislocations. 


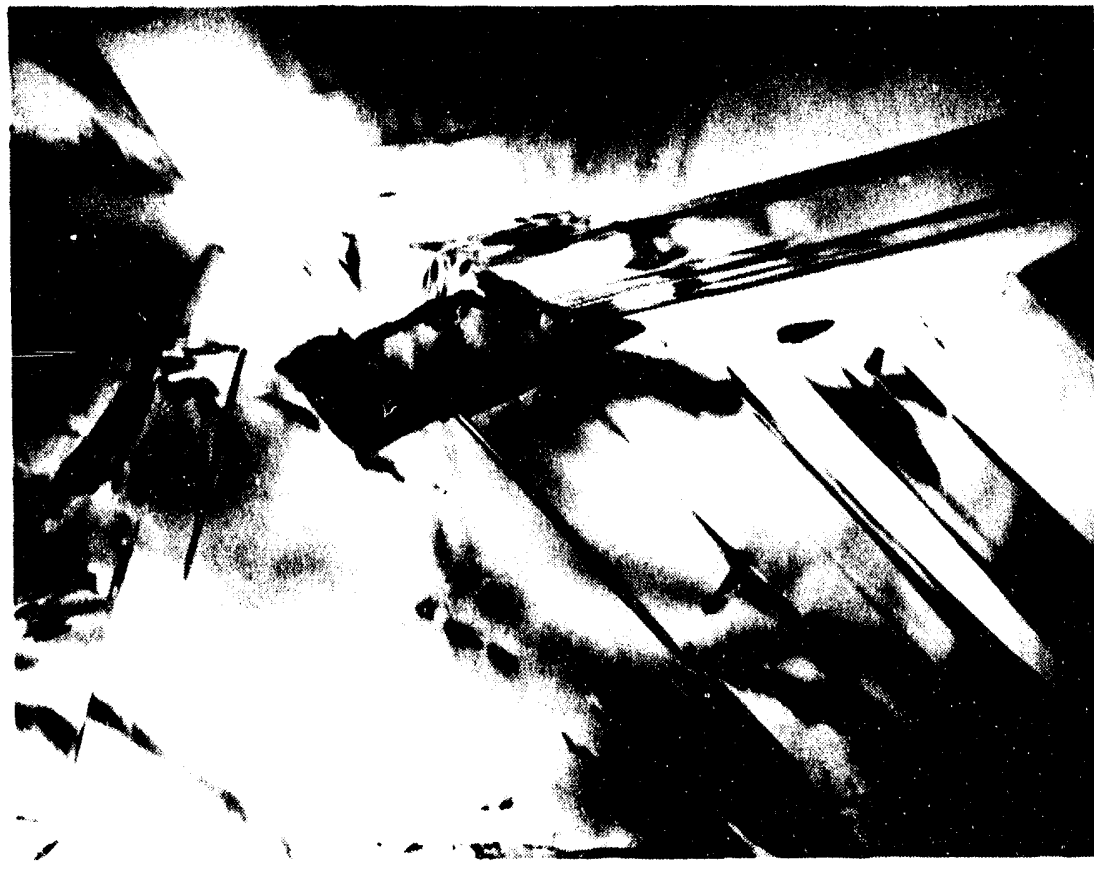

$\underset{0.40 \mu \mathrm{m}}{L}$

Fig. 10 A transmission electron micrograph of a region near midthickness of the Type A silicon carbide. The viewing direction is paraliel to the deposition plane. Stacking faults on \{111\} planes are nearly parallel to the electron beam so they appear as narrow straight bands. A few dislocations are also present. 
they appear as narrow bands. In both cases, the stacking faults were shown to lie on $\{111\}$ planes by selected-area electron diffraction. Many dislocations are observable in Fig. 9, and a few dislocations are observable in Fig. 10. Dislocations were not observed in micrographs of the Type B or Type C silicon carbides. The dislocations were probably present in the as-deposited material because silicon carbide is brittle, and it is therefore unlikely that they were introduced by deformation of the specimen during handling.

The stacking faults observed in the transmission electron micrographs are consistent with observations by Gulden (7) and support the explanation offered in the prior section for differences between the relative magnitudes of some of the $x$-ray diffraction peaks of this silicon carbide and those reported in the Powder File.

Type B Silicon Carbide

An optical micrograph of a polished cross-section of the Type $B$ silicon carbide is shown in Fig. 11. There are just a very few small pores near the substrate surface. Otherwise, no porosity is evident, which is consistent with the high density of the Type $B$ silicon carbide.

An optical micrograph of an electrolytically etched cross section of the Type B silicon carbide is shown in Fig. 12, and a scanning electron micrograph of a cross section of the same material after etching in the molten salt is shown in Fig. 13. The microstructure of this material is similar to that of the Type A silicon carbide. Namely, the grains are small near the substrate surface and large and columnar near the outer surface.

Transmission electron micrographs of the Type B silicon carbide are shown in Figs. 14 and 15 . Fig 14 shows a region near the substrate 

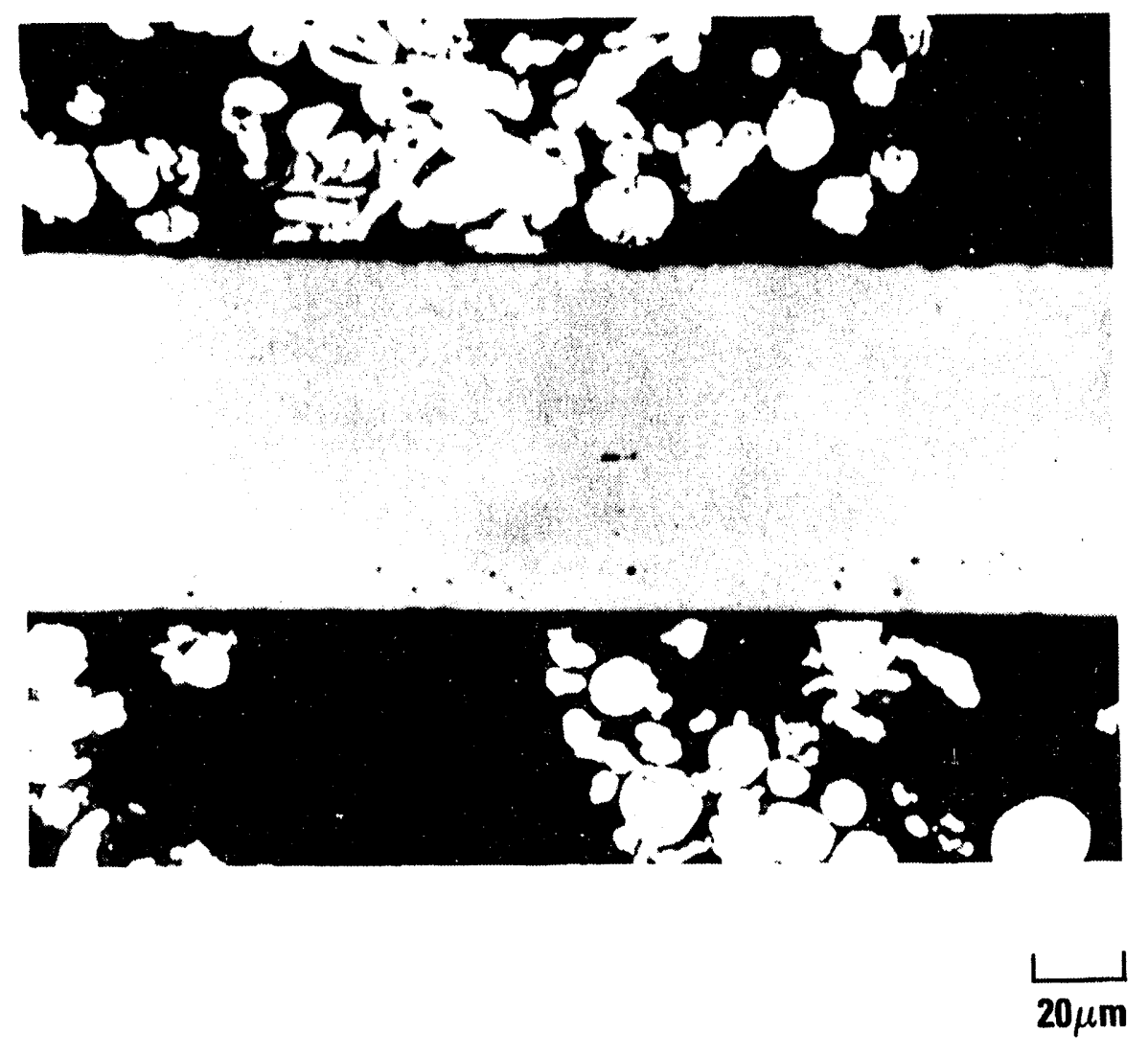

Fig. 11 An optical micrograph of a polished cross section of the Type B silicon carbide. The substrate surface is at the bottom. A few small pores near the substrate surface are evident. Otherwise, no pores are observable in the material. 


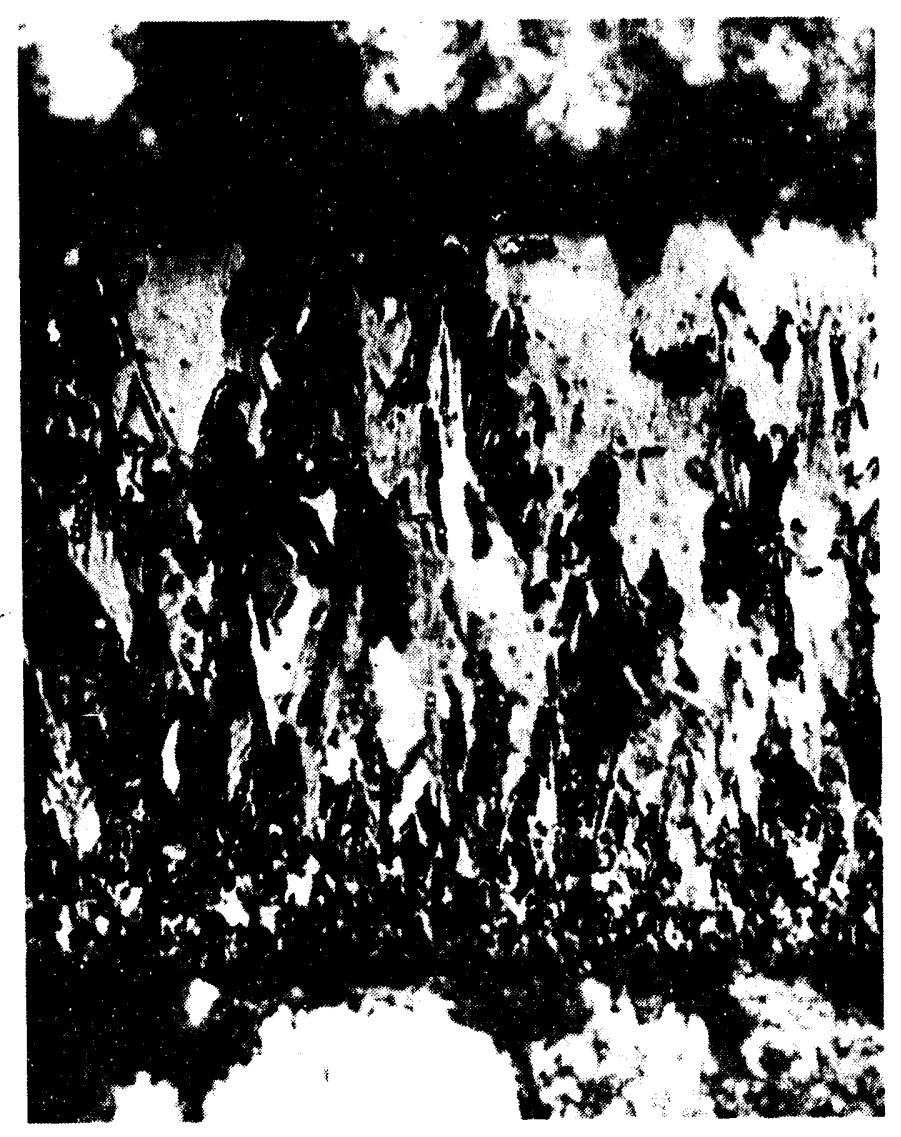

$\underset{10 \mu \mathrm{m}}{L}$

Fig. 12 An optical micrograph of a electrolytically etched cross section of the Type B silicon carbide. The substrate surface is at the bottom. The microstructure appears similar to that of the Type A silicon carbide, i.e., there are small grains near the substrate surface and large grains near the outer surface. 


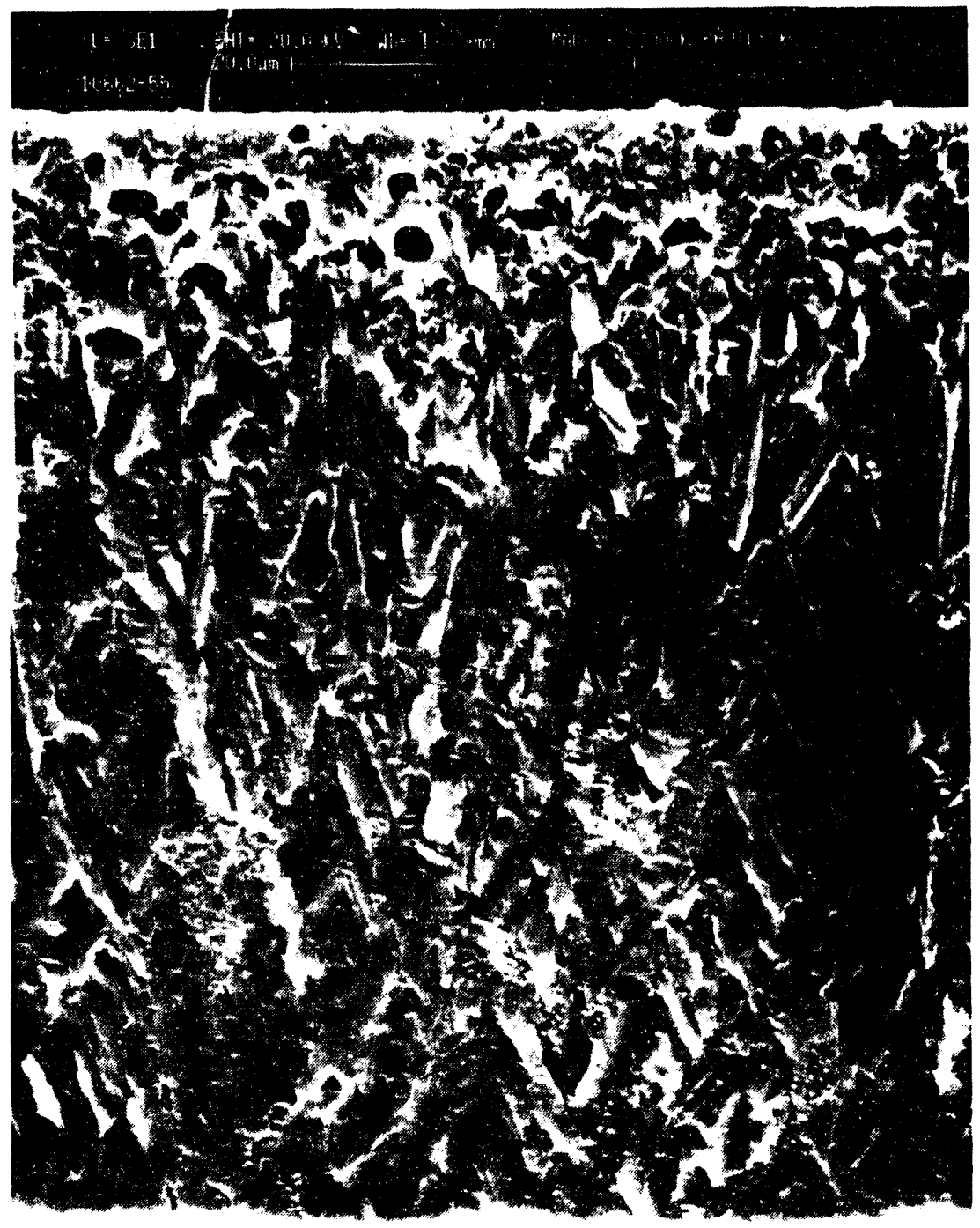

Fig. 13 A scanning electron micrograph of a molten-salt-etched cross section of the Type $B$ silicon carbide. The substrate surface is at the top. The small grains near the substrate surface and the large grains near the outer surface are clearly evident. The pores near the substrate surface have been enlarged by the etching. overall, the grains are smaller than in the Type A silicon carbide. 


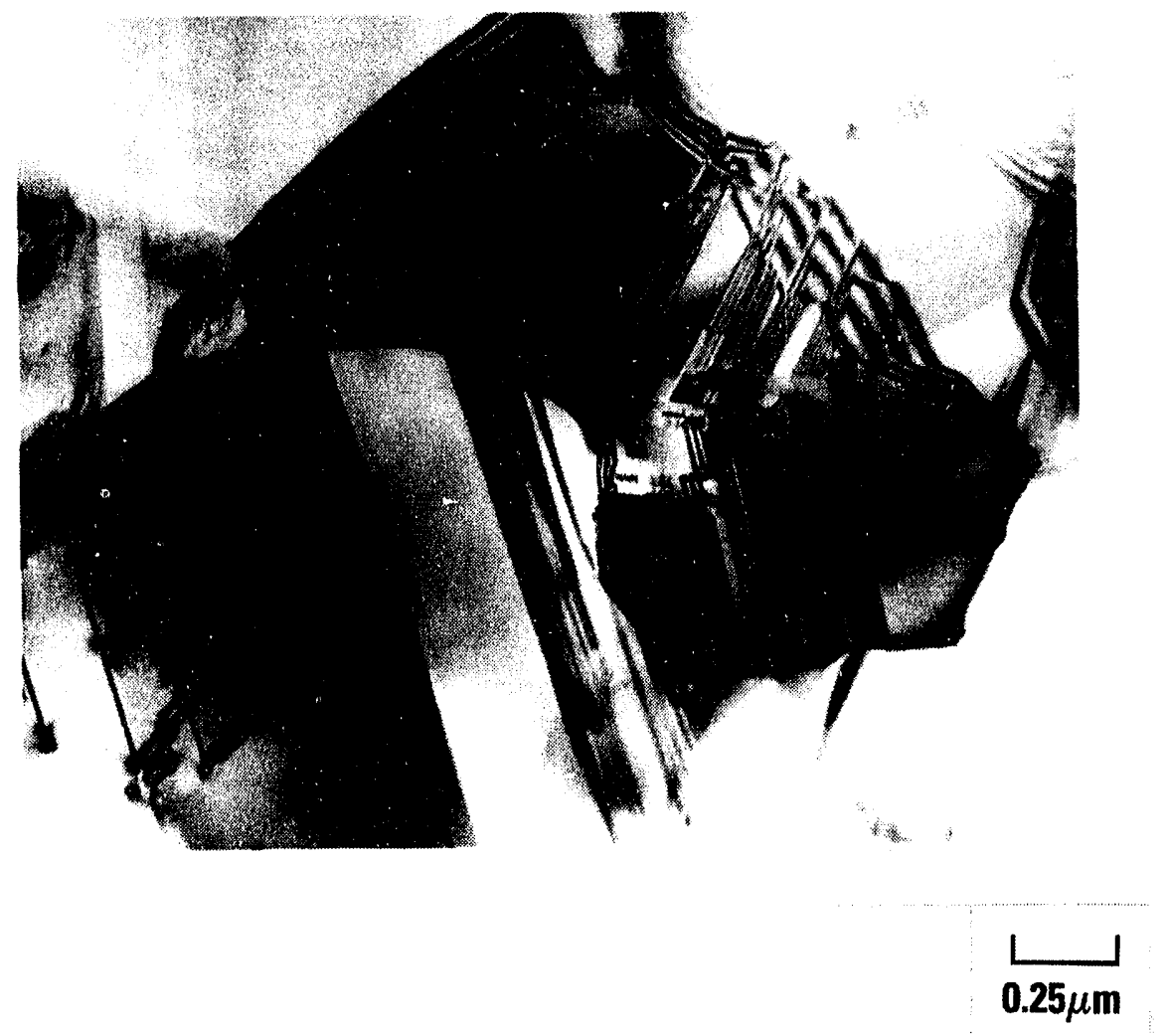

Fig. 14 A transmission electron micrograph of a region near the substrate surface of the Type B silicon carbide. The viewing plane is parallel to the deposition plane. A grain delineated by sets of fringes is present in the middle of the micrograph. Stacking faults on $\{111\}$ planes within this grain are revealed by sets of straight fringes. 


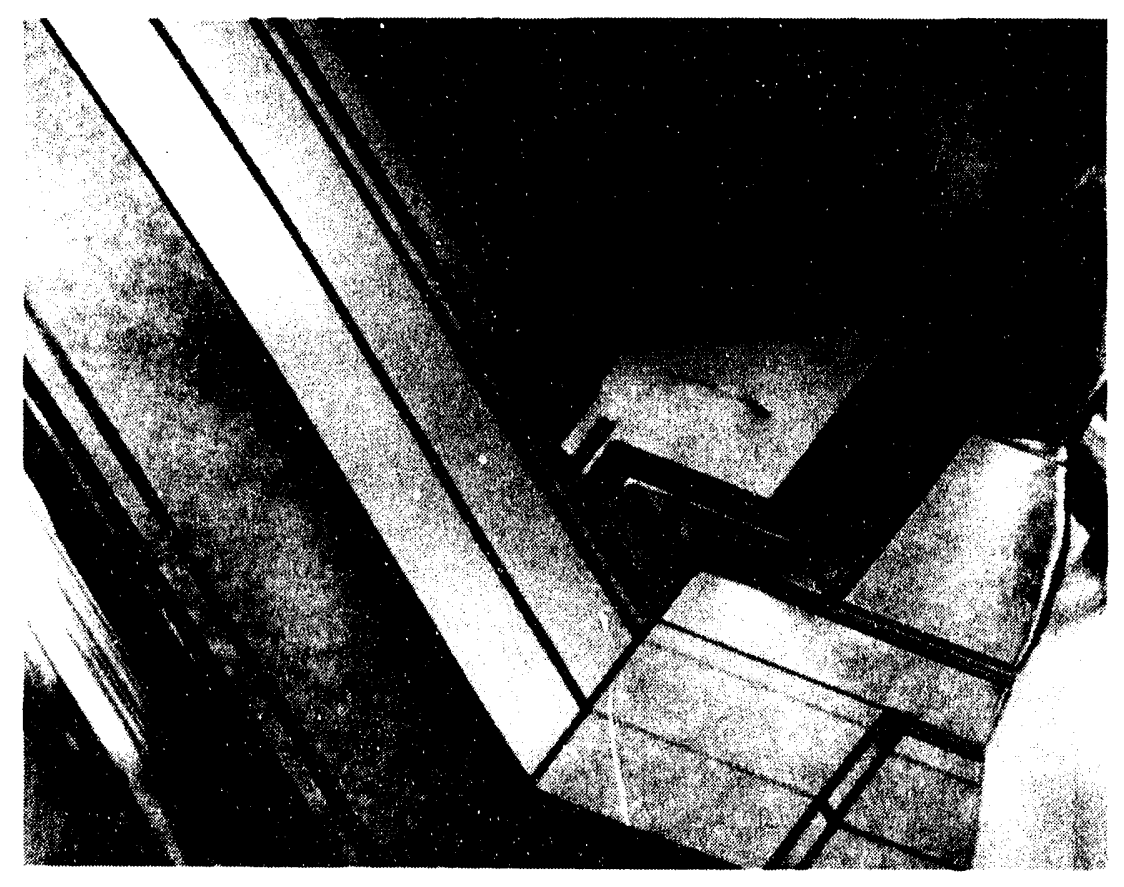

$0.10 \mu \mathrm{m}$

Fig. 15 A transmission electron micrograph of a region near the outer surface of the Type B silicon carbide. The viewing plane is parallel to the deposition plane. stacking faults on $\{111\}$ planes are viewed nearly edge-on so they appear as narrow bands rather than sets of fringes. 
surface, and Fig. 15 shows a region near the outer surface. In both cases, the viewing direction is perpendicular to the deposition plane. The $\{111\}$ stacking faults present in the Type $A$ silicon carbide are also present in the Type B silicon carbide, again supporting the explanation offered for the differences in the relative magnitudes of some of the x-ray diffraction peaks. However, no dislocations are observable in the micrographs of the Type $\mathrm{B}$ silicon carbide.

Type C silicon Carbide

A polished cross section of the Type $C$ silicon carbide is shown in Fig. 16. As opposed to the Type A and Type B silicon carbides, there is porosity present in this material. This is not unexpected because the density of the Type $\mathrm{C}$ silicon carbide is significantly lower than those of the other silicon carbide types.

It was not possible to etch the Type $C$ silicon carbide electrolytically, and once this silicon carbide was etched by other means, it was not possible to resolve the microstructure optically. Highmagnification scanning electron micrographs of etched regions of a cross section of the Type $C$ silicon carbides are shown in Figs. 17 and 18. Fig. 17 is a micrograph of a region near the substrate surface, and Fig 18 is a micrograph of a region near the cuter surface. As can be seen there is no difference in the microstructures of the two regions. The grain size is very small when compared to the Type $A$ and Type $B$ silicon carbides, and the grains are more or less equiaxed as compared to the columnar grains that comprise most of the Type A and Type B silicon carbides.

A transmission electron micrograph of a region near the mid-thickness of one of the Group A5 silicon carbides is shown in Fig. 19 The viewing direction is perpendicular to the deposition plane. Small highly faulted grains make up the microstructure. Note that the $0.5 \mu \mathrm{m}$ grain size observable in this micrograph is consistent 

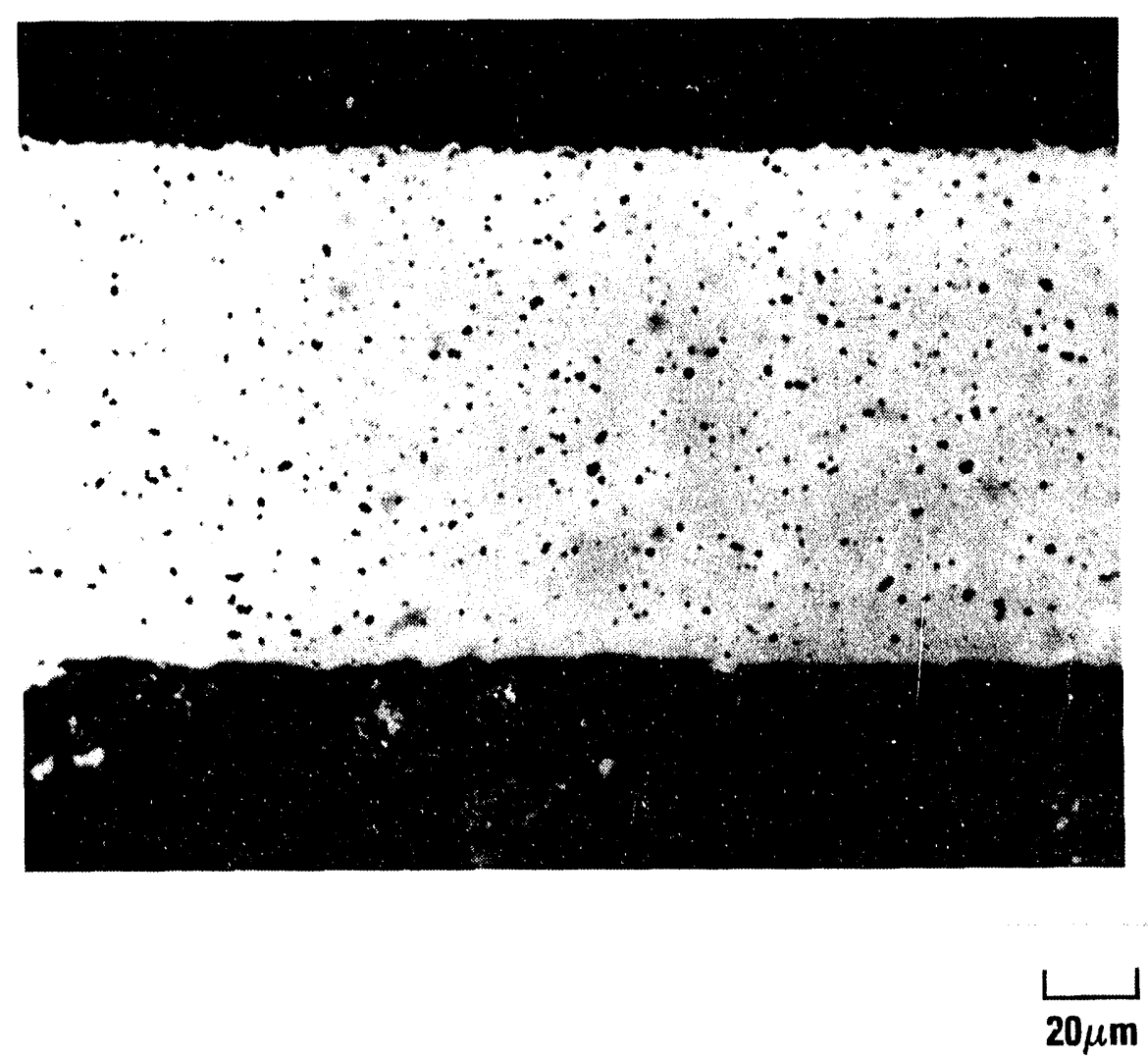

Fig. 16 An optical micrograph of a polished cross section of the Type $C$ silicon carbide. The substrate surface is at the bottom. There is porosity uniformly distributed throughout the material. 


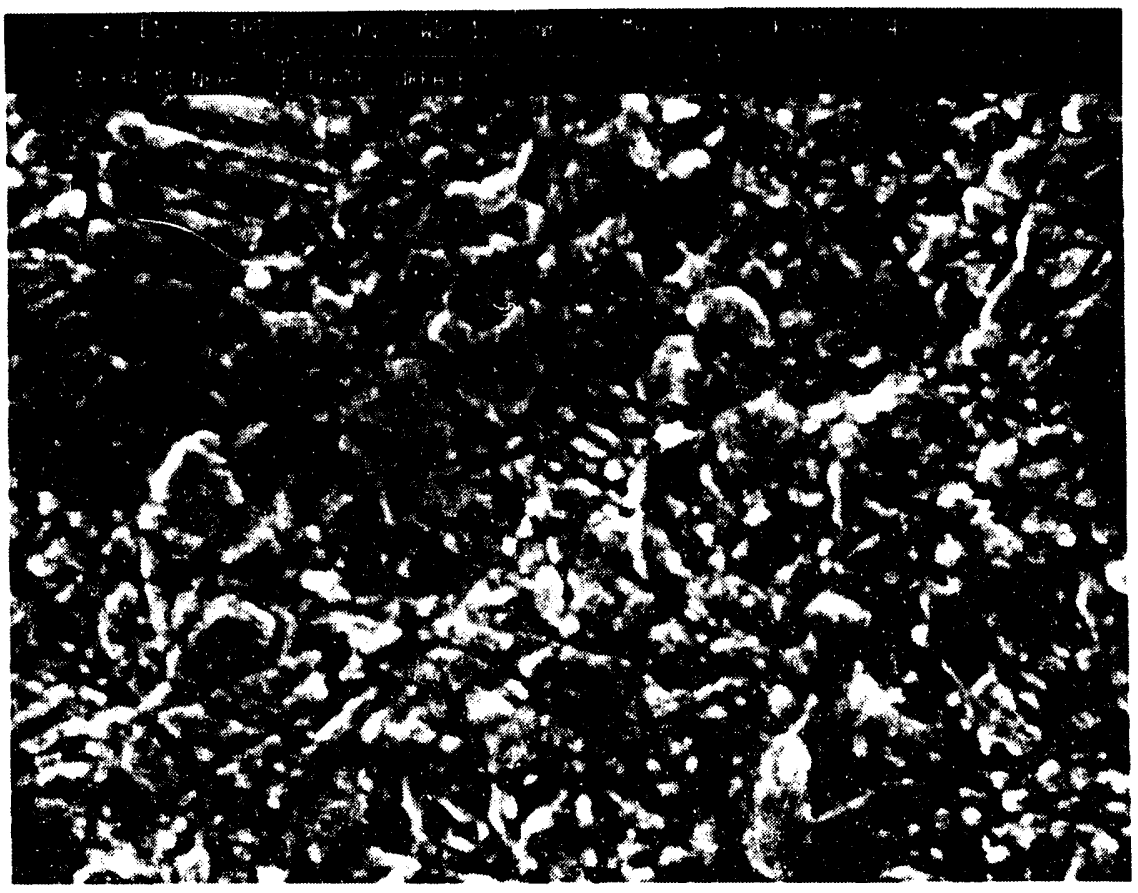

Fig. 17 A scanning electron micrograph of a cross-sectional regional near the substrate surface of the Type $C$ silicon carbide after etching in the $\mathrm{NaOH}-\mathrm{K}_{3} \mathrm{Fe}(\mathrm{CN})_{6}$ mixture. The grain size is very small, and the grains are more or less equiaxed. 


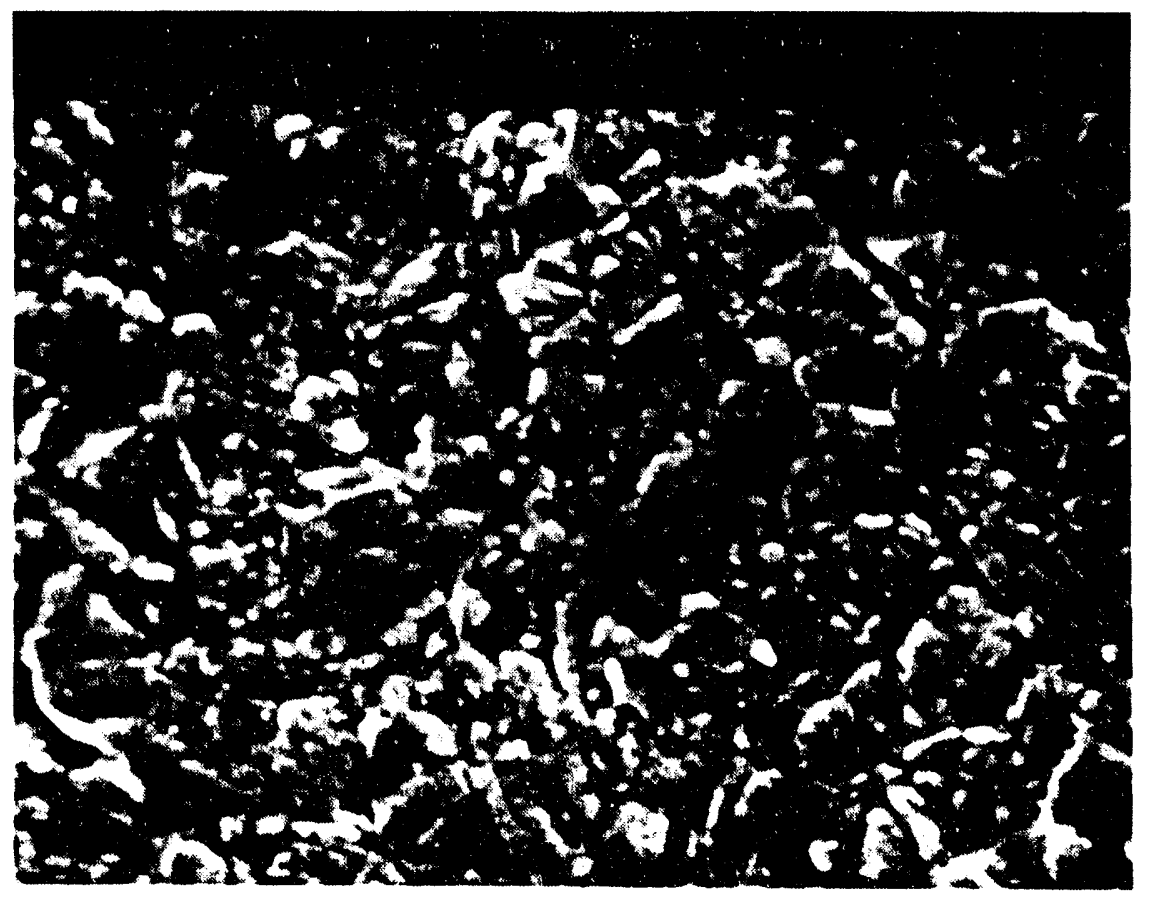

Fig. 18 A scanning electron micrograph of a cross-sectional region near the outer surface of the Type $C$ silicon carbide after etching in the $\mathrm{NaOH}-\mathrm{K}_{3} \mathrm{Fe}(\mathrm{N})_{6}$ mixture. The microstructure is the same as that near the substrate surface. 


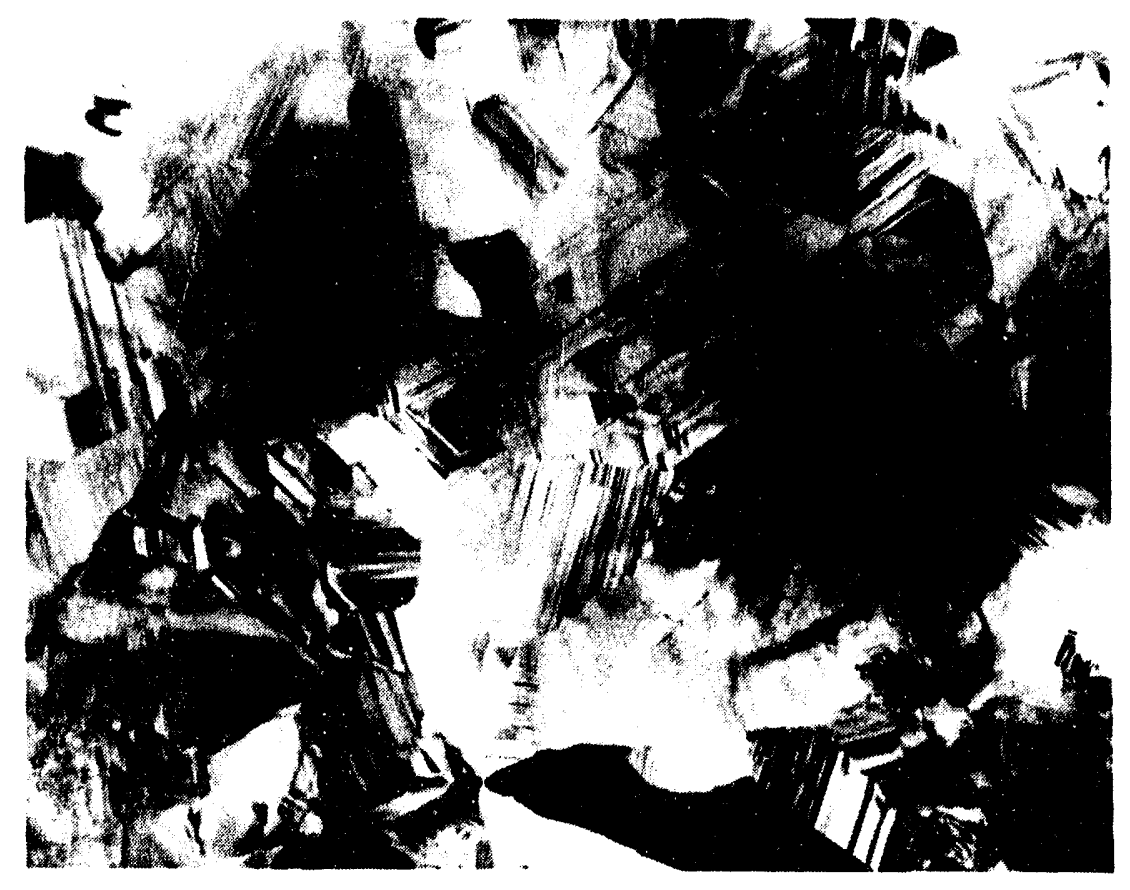

$0.25 \mu \mathrm{m}$

Fig. 19 A transmission electron micrograph of a region near midthickness of the Type $C$ silicon carbide. The viewing direction is perpendicular to the deposition plane. The small highly faulted grains shown in this micrograph are consistent with the microstructure observed on the etched surfaces. 
with that observable in the scanning electron micrographs of the etched specimen. The stacking fault density obviously is higher than in the Type $A$ and Type $B$ silicon carbides, but for reasons that cannot be explained, this did not produce an enhanced suppression of the $\{200\}$ x-ray diffraction peak. 


\section{SUMMARY}

Small silicon carbide slabs $1 \mathrm{~cm}$ square and $75 \mu \mathrm{m}$ thick were produced for investigation of tritium permeation at Sandia National Laboratory by silicon carbide coating graphite blocks that were fluidized along with particles in a laboratory fluidized-bed particle coater. Subsequent to coating the edges of the blocks were cut off and the graphite and a pyrocarbon coating that had been deposited prior to silicon carbide coating to smooth the graphite surface were burned away.

Tritium permeation studies were carried out on silicon carbide types that were deposited at $1700^{\circ} \mathrm{C}, 1550^{\circ} \mathrm{C}$ and $1400^{\circ} \mathrm{C}$ at a nominal deposition rate of $0.3 \mu \mathrm{m} / \mathrm{min}$.

In all cases, $x$-ray diffraction showed these silicon carbides to be the beta or cubic type, and no evidence of second-phase silicon or graphite was found.

Except for the silicon carbide deposited at the lowest deposition temperature of $1400^{\circ} \mathrm{C}$, the silicon carbide densities did not differ significantly from the theoretical value for beta silicon carbide.

The silicon carbides deposited at $1700^{\circ} \mathrm{C}$ and $1550^{\circ} \mathrm{C}$ had preferred orientation of $\{111\}$ and $\{100\}$ crystalline planes parallel to the deposition plane near the outer surface, but there was random orientation of the silicon carbide grains near the substrate surface. The silicon carbide deposited at $1400^{\circ} \mathrm{C}$ had a random orientation of the silicon carbide grains throughout the deposit.

The microstructures of the silicon carbides were studied by optical, scanning electron and transmission electron microscopy. 
The $1700^{\circ} \mathrm{C}$ deposit had no apparent porosity, a very thin smallgrained region near the substrate surface and large columnar-shaped grains elsewhere. The $1550^{\circ} \mathrm{C}$ deposit had some small pores near the substrate surface, a thicker small-grained region near the substrate surface and smaller columnar-shaped grains. The $1400^{\circ} \mathrm{C}$ deposit had a uniform distribution of pores and small near equiaxed grains. The silicon carbide grains in all of the deposits contained stacking faults on $\{111\}$ planes. 


\section{REFERENCES}

1. Erro Gyarmati and Helmut Hoven, "A Method of Electrolytically Etching Pyrolytic silicon Carbide", Praktische Metallographic, V11, 117 .

2. T.D. Gulden, "Deposition and Microstructure of Vapor-Deposited silicon Carbide", J. American Ceramic Soc., 51, 424 (1968).

3. C.R. Clark, Private Communication.

4. R.J. Price, "Properties of Silicon Carbide for Nuclear Fuel Particle Coatings", Nuclear Tech., 35, 320 (1977).

5. Powder Diffraction File, International Centre for Diffraction Data, Swarthmore, PA., USA.

6. J. Chin, P.K. Gantzel and R.G. Hudson, "The structure of Chemical Vapor Deposited Silicon Carbide", Thin Solid Films, 40,57 (1977).

7. T.D. Gulden, "Stacking Faults in Chemically-Vapor-Deposited Beta Silicon Carbide", J. American Ceramic Soc., 54, 498 (1971). 
UNLIMITED RELEASE

INITIAL DISTRIBUTION:

$8000 \quad$ J. C. Crawford

$8300 \quad$ W. J. McLean

8347 R. A. Causey (50)

8700 R. C. Wayne

8535 Publications for OSTI (10)

8535 Publications/Technical Library Processes, 7141

$7141 \quad$ Technical Library Processes Department (3)

8523-2 Central Technical Files (3) 

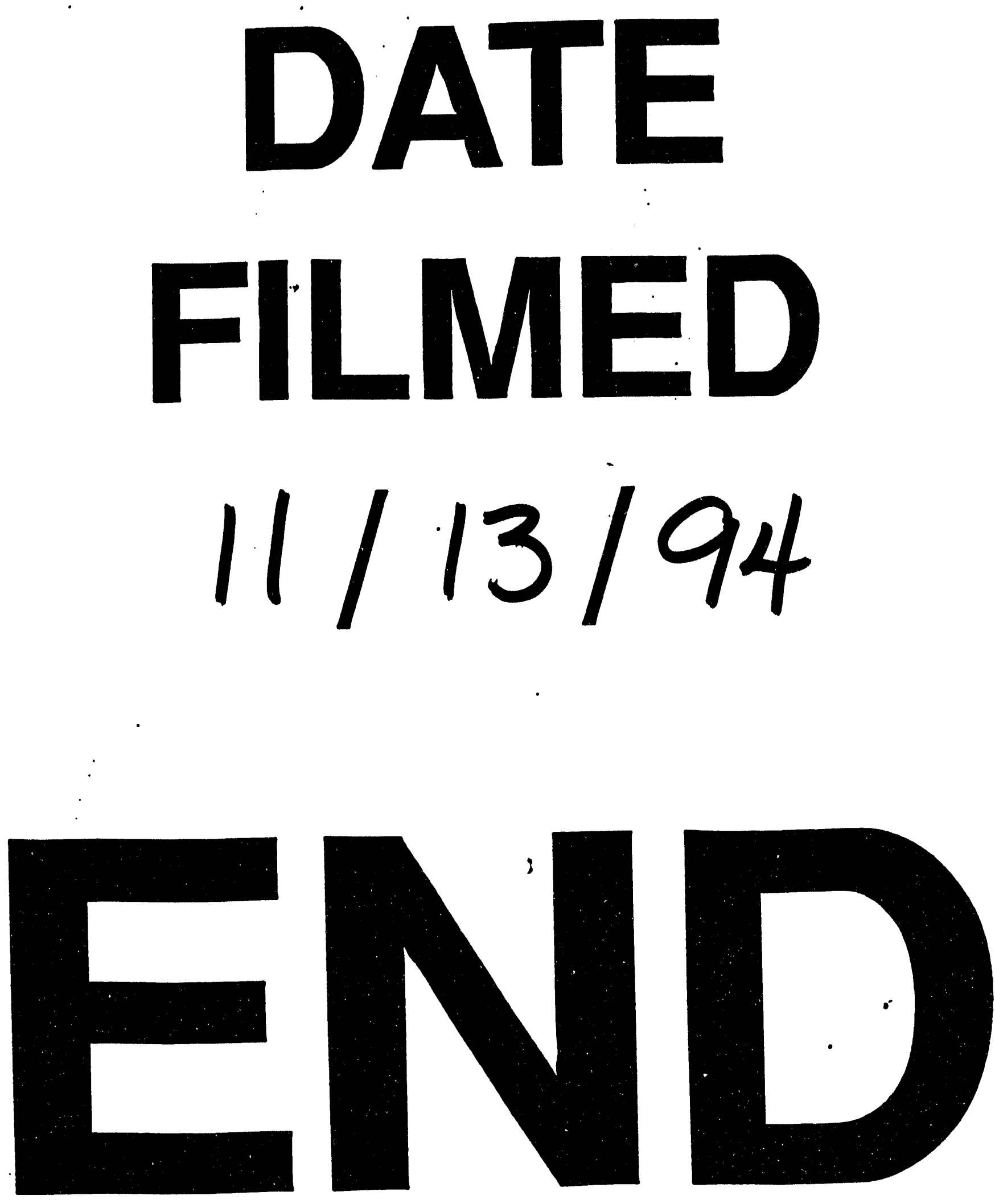
